\title{
Triphenylquinoline (TPQ)-based dual-state emissive probe for cell imaging in multicellular tumor spheroids
}

Wenbo Dai, ${ }^{\dagger}$ Pai Liu, ${ }^{\dagger}$ Shuai Guo, ${ }^{\dagger}$ Zhiqi Liu, ${ }^{\dagger}$ Mengni Wang, ${ }^{\dagger}$ Jianbing Shi, ${ }^{\dagger}$ Bin Tong, ${ }^{\dagger}$

Tianqing Liu, * Zhengxu Cai, *广 and Yuping Dong ${ }^{\dagger}$

${ }^{\dagger}$ Beijing Key Laboratory of Construction Tailorable Advanced Functional Materials and Green Applications, School of Materials Science \&

Engineering, Beijing Institute of Technology, 5 South Zhongguancun Street, Beijing, 100081, China.

* QIMR Berghofer Medical Research Institute, 300 Herston Road, Brisbane, QLD 4006, Australia.

*E-mail: caizx@bit.edu.cn; michelle.tianqing.liu@gmail.com. 


\section{Materials and Characterization:}

All chemicals were purchased from Alfa Aesar and Beijing chemical reagent company and were used without further purification. THF was freshly distilled from sodium. Solvents were purified and dried according to standard procedures. All manipulations were conducted with Schleck tube. The structures of the products were identified by Mass Spectrum (MS), ${ }^{1} \mathrm{H}$ NMR and ${ }^{13} \mathrm{C}$ NMR spectra through Finnigan BIFLEX III mass spectroscopy and a Bruker ARX 400 spectrometer, respectively. The UV-visible absorption spectra were measured on a Persee TU-1901 UV-vis spectrophotometer. The photoluminescence spectra were collected on a Hitachi F-7000 spectrophotometer. X-ray crystal structure analyses were measured on BrukerAXS SMART APEX2 CCD diffractometer. Solid-state emission quantum yields $\left(\Phi_{\mathrm{F}}\right)$ were collected on a FluoroMax-4 (Horiba Jobin Yvon) fluorometer equipped contains an integrated sphere.

The theoretical ground-state geometry and electronic structure of TPQ-based molecules were optimized by using the density functional theory (DFT) with B3LYP hybrid functional at the basis set level of $6-31+G(d, p)$. All the theoretical calculations were performed using Gaussian 03 package.

Lippert-Mataga equation:

$$
\begin{gathered}
\Delta v \equiv v_{\mathrm{ab}}-v_{\mathrm{em}}=\frac{2 \Delta f}{h c a^{3}}\left(\mu_{\mathrm{e}}-\mu_{\mathrm{g}}\right)^{2}+\text { const } \\
\Delta f=\frac{\varepsilon-1}{2 \varepsilon+1}-\frac{n^{2}-1}{2 n^{2}+1}
\end{gathered}
$$

$\Delta v$ is the Stokes shift, $\Delta f$ is the solvent polarity parameter, $h$ is the Planck 
constant, $c$ is the speed of light, $a$ is the Onsager cavity radius, $\mu_{\mathrm{e}}$ and $\mu_{\mathrm{g}}$ refer to the dipolar moments in the excited and ground states, and $\varepsilon$ and $\mathrm{n}$ are the dielectric constant and refractive index of the solvent, respectively.

HeLa cells were seeded in $\Phi 20 \mathrm{~mm}$ glass bottom cell culture dishes $(8 \pm 0.03$ $\times 10^{5}$ cells in each dish). All the cell lines were grown overnight in a humidified incubator at $37^{\circ} \mathrm{C}$ with $5 \% \mathrm{CO}_{2}$ atmosphere. TPQ-TPA was dissolved in DMSO $\left(1 \times 10^{-3} \mathrm{~mol} / \mathrm{L}\right)$ and diluted with $\operatorname{DMEM}\left(1 \times 10^{-5} \mathrm{~mol} / \mathrm{L}\right)$. After being incubated with TPQ-TPA $\left(1 \times 10^{-5} \mathrm{~mol} / \mathrm{L}\right.$ in DMEM $)$. All cells were washed with PBS ( $\mathrm{pH}=7.4)$ solution for three times followed by fresh culture medium replenish.

\section{Cytotoxicity Studies:}

HeLa cells were stained with $1 \times 10^{-5} \mathrm{~mol} / \mathrm{L}$ TPQ-TPA solution for $24 \mathrm{~h}, 48$ h, and 72 h, respectively. Cell apoptosis was measured by Annexin V-FITC/PI Apoptosis Detection Kit. Cells were digested with $0.05 \%$ Trypsin and stained with annexin V-FITC and propidium iodide in the dark at room temperature according to the manufacturer's instructions. After treatment at a given time, $400 \mu \mathrm{L} 1 \mathrm{x}$ Annexin V binding solution was added into each sample. Apoptotic cells were measured by a flow cytometer.

3D viability assays: 
HeLa tumor spheroids were formed using the microwell-based methods published previously. ${ }^{1}$ The devices were hydrated with cell culture medium for 30 min before seeding cells. HeLa cells $(200 \mu \mathrm{L})$ were seeded to enable 1000 cells per well and incubated in the devices for seven days. The tumor spheroids were monitored with a light microscope until the size of tumor spheroids reached around $500 \mu \mathrm{m}$ in diameter. To understand the biocompatibility of TPQ-TPA to 3D tumor tissue spheroids, TPQTPA solution $\left(1 \times 10^{-5} \mathrm{~mol} / \mathrm{L}\right)$ was incubated with HeLa tumor spheroids for 2,6 , or 12 h. After fixation and washing, the tumor tissue spheroids were dehydrated, embedded in paraffin, and then cut into 5- $\mu$ m-thick histologic sections. Hematoxylin and eosin (H\&E) staining was performed using a Leica Autostainer XL (ST5015, Leica Microsytem, North Ryde, Australia). The stained tissue sections were analysed by light microscopy.

\section{Penetration of TPQ-TPA inside 3D HeLa tumor spheroids:}

The 3D tumor spheroids were then treated with TPQ-TPA solution $\left(1 \times 10^{-}\right.$ ${ }^{5} \mathrm{~mol} / \mathrm{L}$ ) for 2,6 , or $12 \mathrm{~h}$. After the treatment, the tumor spheroids were washed with PBS twice and then fixed with 4\% formaldehyde for 2 h. After washing with PBS, the penetration of TPQ-TPA through the tumor spheroids was imaged with LSM710 confocal laser-scanning upright microscopes (Zeiss) with the center of $3 \mathrm{D}$ tumor spheroids as the focal plane.

\section{Synthesis of TPQ derivatives:}


Synthesis of 4: To a $100 \mathrm{~mL}$ round-bottom flask were added benzaldehyde 1 (1.06 g, $10 \mathrm{mmol})$, phenylacetylene $2(1.02 \mathrm{~g}, 10 \mathrm{mmol})$, and 4-bromoaniline 3 (1.72 g, $10 \mathrm{mmol}), \mathrm{FeCl}_{3}(162 \mathrm{mg}, 1 \mathrm{mmol})$ and $15 \mathrm{~mL}$ of 1, 2-dichloroethane (DCE) The reaction mixture was then stirred in an oil bath at $120{ }^{\circ} \mathrm{C}$ until the substrates were consumed completely (about $12 \mathrm{~h}$ ), and then it was cooled to room temperature and the solvent was evaporated, the residue was purified by column chromatograph (hexane/DCM) $(3: 1, \mathrm{v} / \mathrm{v})$ to afford the desired product. $4(2.27 \mathrm{~g}, 63 \%):{ }^{1} \mathrm{H}$ NMR $\left(400 \mathrm{MHz}, \mathrm{CDCl}_{3}\right) \delta 8.21-8.17(\mathrm{~m}, 2 \mathrm{H}), 8.12(\mathrm{~d}, J$ $=8.8 \mathrm{~Hz}, 1 \mathrm{H}), 8.05(\mathrm{~d}, J=2.0 \mathrm{~Hz}, 1 \mathrm{H}), 7.84(\mathrm{~s}, 1 \mathrm{H}), 7.80(\mathrm{dd}, J=9.0,2.2 \mathrm{~Hz}$, $1 \mathrm{H}), 7.59-7.47(\mathrm{~m}, 8 \mathrm{H}) .{ }^{13} \mathrm{C} \mathrm{NMR}\left(101 \mathrm{MHz}, \mathrm{CDCl}_{3}\right) \delta 157.16,148.36,147.40$, $139.15,137.70,133.01,131.84,129.64,129.45,128.91,128.84,128.73,127.78$, 127.55, 126.98, 120.45, 120.02. MS (ESI) m/z calcd. for $\mathrm{C}_{21} \mathrm{H}_{14} \mathrm{BrN} 360.03$ $[\mathrm{M}]^{+}$, found $361.03[\mathrm{M}+1]^{+}$.

Synthesis of TPQ-R: Compound $4(0.54 \mathrm{~g}, 1.5 \mathrm{mmol})$, phenylboronic acid 5a (0.27 g, $2.25 \mathrm{mmol}$ for TPQ) or 4-methoxyphenylboronic acid 5b (0.34 g, $\left.2.25 \mathrm{mmol}_{\text {for }} \mathbf{T P Q}-\mathbf{O C H}_{3}\right)$ or 4-(diphenylamino)phenylboronic acid 5c (0.65 g, $2.25 \mathrm{mmol}$ for TPQ-TPA) or 4-cyanophenylboronic acid 5d (0.33 g, 2.25 mmol for TPQ-CN), $\mathrm{Pd}\left(\mathrm{PPh}_{3}\right)_{4}(0.17 \mathrm{~g}, 0.15 \mathrm{mmol}), \mathrm{K}_{2} \mathrm{CO}_{3}(0.21 \mathrm{~g}, 1.5 \mathrm{mmol})$ in $21 \mathrm{~mL}$ toluene and $9 \mathrm{ml}$ methanol were heated under reflux for $14 \mathrm{~h}$. Then the solution was cooled to room temperature. After removal of solvent under reduced pressure, the crude product was purified by column chromatography 
(hexane/DCM) to afford pure target compound.

TPQ (0.40 g, 75\%): ${ }^{1} \mathrm{H}$ NMR $\left(400 \mathrm{MHz}, \mathrm{CDCl}_{3}\right) \delta 8.34(\mathrm{~d}, J=8.8 \mathrm{~Hz}, 1 \mathrm{H})$, $8.24(\mathrm{~d}, J=7.6 \mathrm{~Hz}, 2 \mathrm{H}), 8.11(\mathrm{~s}, 1 \mathrm{H}), 8.03(\mathrm{~d}, J=8.8 \mathrm{~Hz}, 1 \mathrm{H}), 7.86(\mathrm{~s}, 1 \mathrm{H})$, 7.68-7.41 (m, 12H), $7.39(\mathrm{t}, J=7.6 \mathrm{~Hz}, 1 \mathrm{H}) .{ }^{13} \mathrm{C} \mathrm{NMR}\left(101 \mathrm{MHz}, \mathrm{CDCl}_{3}\right) \delta$ $156.80,149.45,148.17,140.68,139.55,139.14,138.40,130.54,129.61,129.46$, $129.34,128.92,128.75,128.55,127.63,127.47,125.96,123.44,119.84 . \mathrm{MS}$ (ESI) $\mathrm{m} / \mathrm{z}$ calcd. for $\mathrm{C}_{27} \mathrm{H}_{19} \mathrm{~N} 357.15[\mathrm{M}]^{+}$, found $358.16[\mathrm{M}+1]^{+}$. Anal. calcd for $\mathrm{C}_{27} \mathrm{H}_{19} \mathrm{~N}$ : C, 90.72; H, 5.36; N, 3.92. Found: C, 90.65; H, 5.47; N, 3.94.

TPQ-OCH $3(0.44 \mathrm{~g}, 76 \%):{ }^{1} \mathrm{H}$ NMR $\left(400 \mathrm{MHz}, \mathrm{CDCl}_{3}\right) \delta 8.32(\mathrm{~d}, J=8.4$ $\mathrm{Hz}, 1 \mathrm{H}), 8.23(\mathrm{~d}, J=7.6 \mathrm{~Hz}, 2 \mathrm{H}), 8.05(\mathrm{~s}, 1 \mathrm{H}), 7.99(\mathrm{~d}, J=8.4 \mathrm{~Hz}, 1 \mathrm{H}), 7.84$ (s, 1H), 7.69-7.44 (m, 10H), $7.00(\mathrm{~d}, J=7.6 \mathrm{~Hz}, 2 \mathrm{H}), 3.85(\mathrm{~s}, 3 \mathrm{H}) .{ }^{13} \mathrm{C} \mathrm{NMR}$ $\left(101 \mathrm{MHz}, \mathrm{CDCl}_{3}\right) \delta 159.45,156.48,138.74,138.46,133.11,130.41,129.60$ $129.40,129.15,128.89,128.73,128.49,127.60,126.01,122.58,119.79,114.38$, 55.40. MS (ESI) $\mathrm{m} / \mathrm{z}$ calcd. for $\mathrm{C}_{28} \mathrm{H}_{21} \mathrm{NO} 387.16[\mathrm{M}]^{+}$, found $388.17[\mathrm{M}+1]^{+}$. Anal. calcd for $\mathrm{C}_{28} \mathrm{H}_{21} \mathrm{NO}$ : C, 86.79; H, 5.46; N, 3.61. Found: C, 86.39; H, 5.59; $\mathrm{N}, 3.59$.

TPQ-TPA $(0.56 \mathrm{~g}, 72 \%):{ }^{1} \mathrm{H}$ NMR $\left(400 \mathrm{MHz}, \mathrm{CDCl}_{3}\right) \delta 8.32(\mathrm{~d}, J=6.8 \mathrm{~Hz}$, $1 \mathrm{H}), 8.21(\mathrm{~d}, J=7.6 \mathrm{~Hz}, 2 \mathrm{H}), 8.05(\mathrm{~s}, 1 \mathrm{H}), 8.00(\mathrm{~d}, J=8.8 \mathrm{~Hz}, 1 \mathrm{H}), 7.82(\mathrm{~s}$, 1H), 7.64-7.42 (m, 10H), 7.31-7.21 (m, 4H), $7.13(\mathrm{~d}, J=8.4 \mathrm{~Hz}, 6 \mathrm{H}), 7.05(\mathrm{t}$, $J=7.2 \mathrm{~Hz}, 2 \mathrm{H}) .{ }^{13} \mathrm{C} \mathrm{NMR}\left(101 \mathrm{MHz}, \mathrm{CDCl}_{3}\right) \delta 156.43,147.60,147.54,138.61$, $138.42,134.11,129.60,129.47,129.35,129.07,128.91,128.74,128.61,128.05$, 127.64, 126.05, 124.63, 123.65, 123.18, 122.49, 119.82. MS (ESI) m/z calcd. 
for $\mathrm{C}_{39} \mathrm{H}_{28} \mathrm{~N}_{2} 524.23[\mathrm{M}]^{+}$, found $525.23[\mathrm{M}+1]^{+}$. Anal. calcd for $\mathrm{C}_{39} \mathrm{H}_{28} \mathrm{~N}_{2}: \mathrm{C}$, 89.28; H, 5.38; N, 5.34. Found: C, 88.95; H, 5.55; N, 5.20.

TPQ-CN (0.46 g, 81\%): ${ }^{1} \mathrm{H} \mathrm{NMR}\left(400 \mathrm{MHz}, \mathrm{CDCl}_{3}\right) \delta 8.36(\mathrm{~d}, J=8.7 \mathrm{~Hz}$, $1 \mathrm{H}), 8.24(\mathrm{~d}, J=7.6 \mathrm{~Hz}, 2 \mathrm{H}), 8.11(\mathrm{~s}, 1 \mathrm{H}), 7.98(\mathrm{~d}, J=8.8 \mathrm{~Hz}, 1 \mathrm{H}), 7.88(\mathrm{~s}$, $1 \mathrm{H}), 7.74(\mathrm{t}, J=8.4 \mathrm{~Hz}, 4 \mathrm{H}), 7.63-7.46(\mathrm{~m}, 8 \mathrm{H}) .{ }^{13} \mathrm{C} \mathrm{NMR}\left(101 \mathrm{MHz}, \mathrm{CDCl}_{3}\right)$ $\delta 157.54,149.61,148.65,145.10,139.25,138.05,136.91,132.71,131.11$, $129.72,129.54,128.96,128.88,128.77,128.61,128.00,127.65,125.92,124.24$, 120.11, 118.85, 111.17. MS (ESI) m/z calcd. for $\mathrm{C}_{28} \mathrm{H}_{18} \mathrm{~N}_{2} 382.15[\mathrm{M}]^{+}$, found $383.15[\mathrm{M}+1]^{+}$. Anal. calcd for $\mathrm{C}_{28} \mathrm{H}_{18} \mathrm{~N}_{2}: \mathrm{C}, 87.93 ; \mathrm{H}, 4.74 ; \mathrm{N}, 7.32$. Found: $\mathrm{C}$, 87.61; H, 4.96; N, 7.45.

\section{The TGA results of TPQ derivatives:}

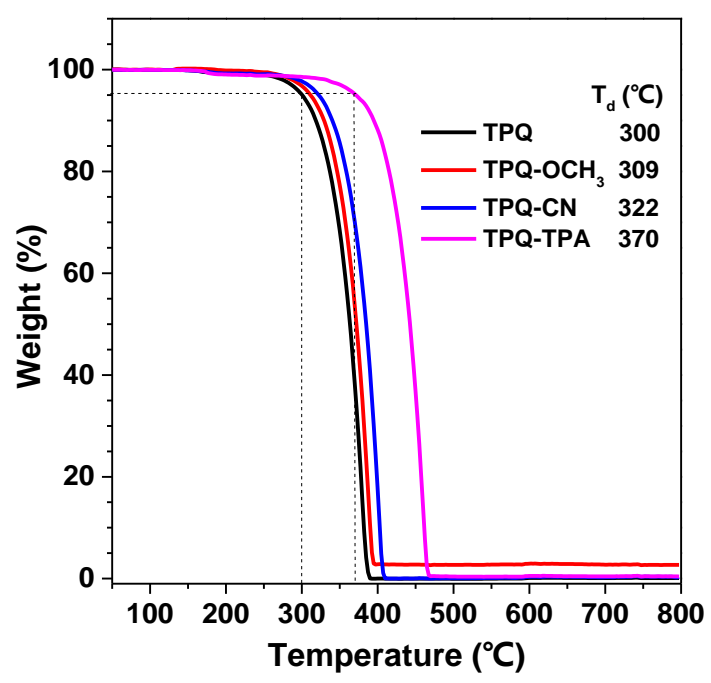

Figure S1. Thermograms analysis of TPQ derivatives. The measurement was performed under $\mathrm{N}_{2}$ at the heating rate of $10{ }^{\circ} \mathrm{C} / \mathrm{min}$.

\section{Photophysical properties:}



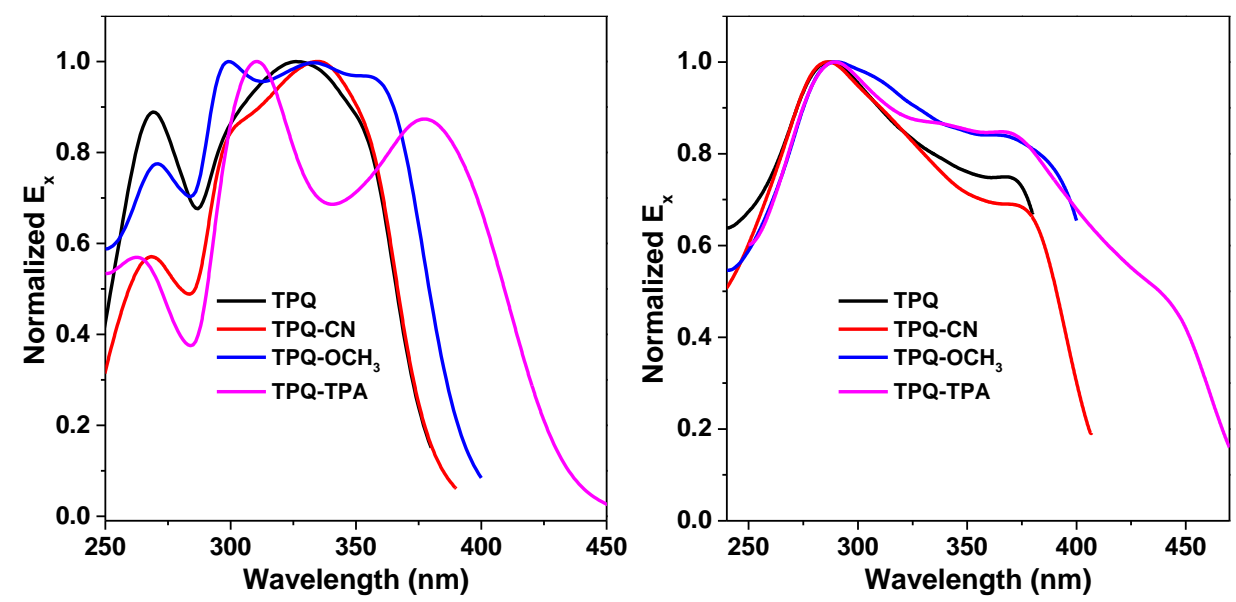

Figure S2. (Left) Excitation spectra of TPQ derivatives in THF solution, concentration: $1 \times 10^{-5} \mathrm{~mol} / \mathrm{L}$. (Right) Excitation spectra of TPQ derivatives in solid state.
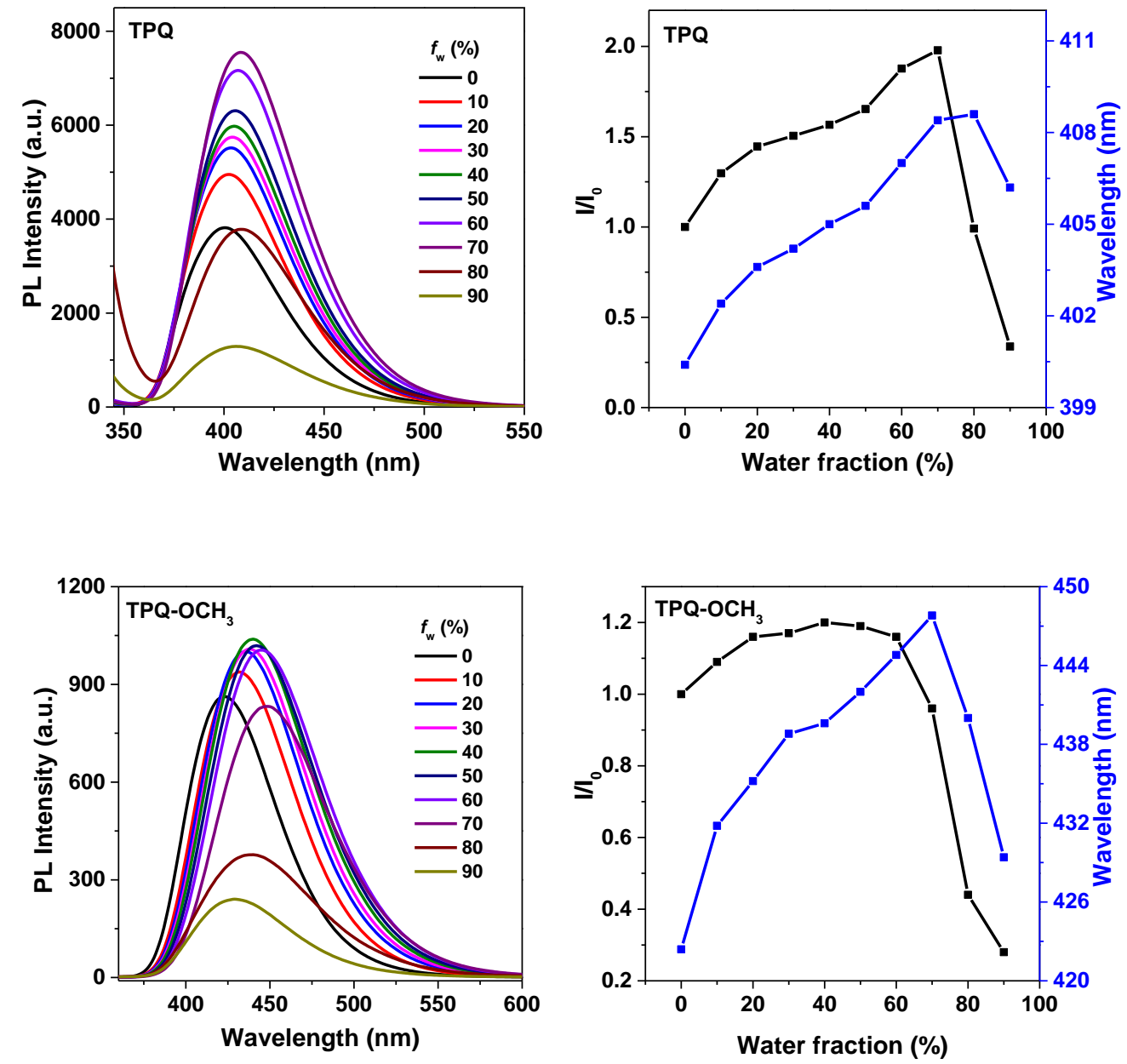

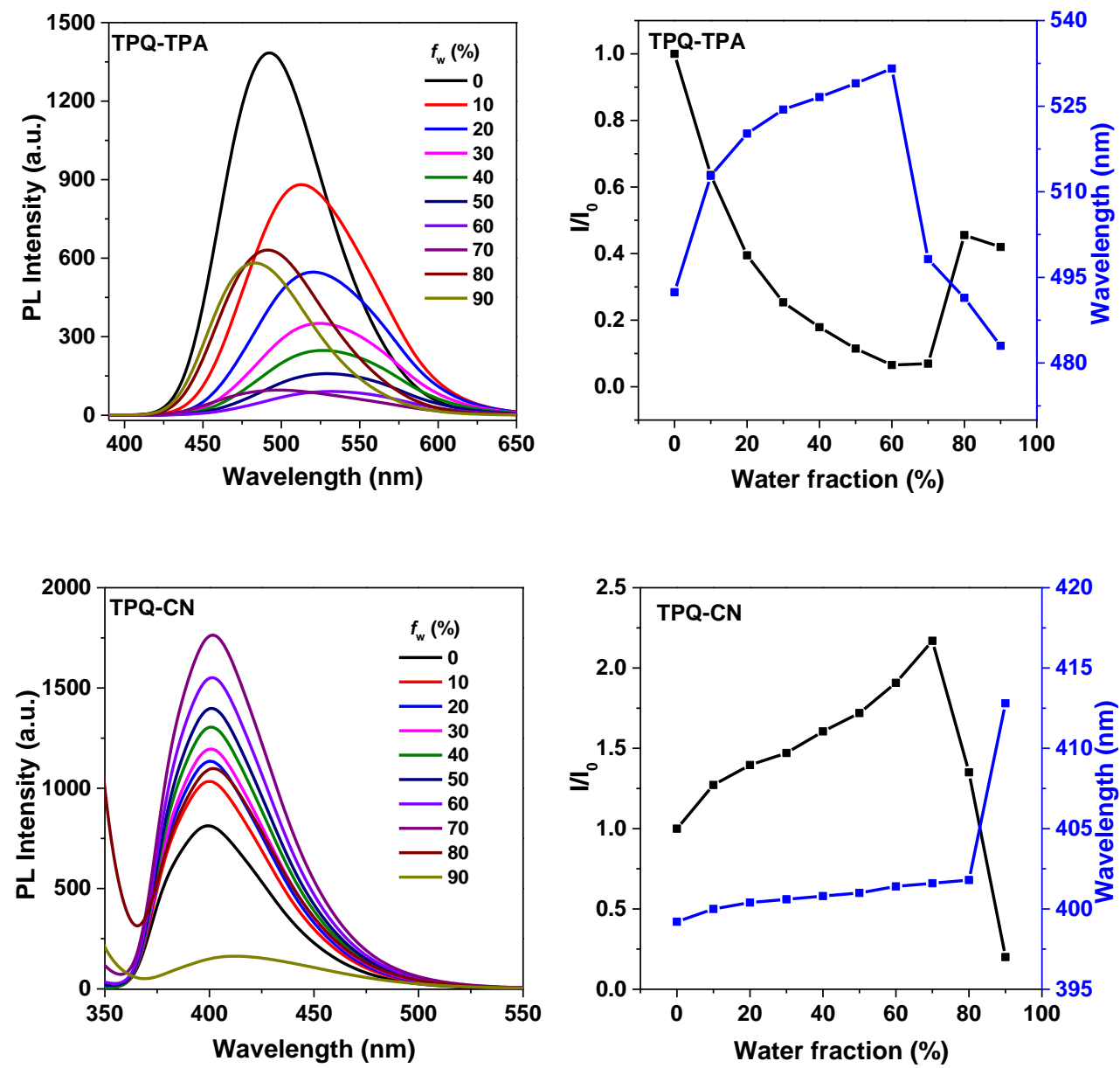

Figure S3. (Left) Fluorescence spectra of TPQ derivatives in THF/water mixtures with different water volume fractions $\left(f_{\mathrm{w}}\right)$. (Right) Fluorescence intensity and emission wavelength of TPQ derivatives in THF/water versus $f_{\mathrm{w}}$. (Concentration: $1 \times 10^{-5} \mathrm{~mol} / \mathrm{L}$ ).
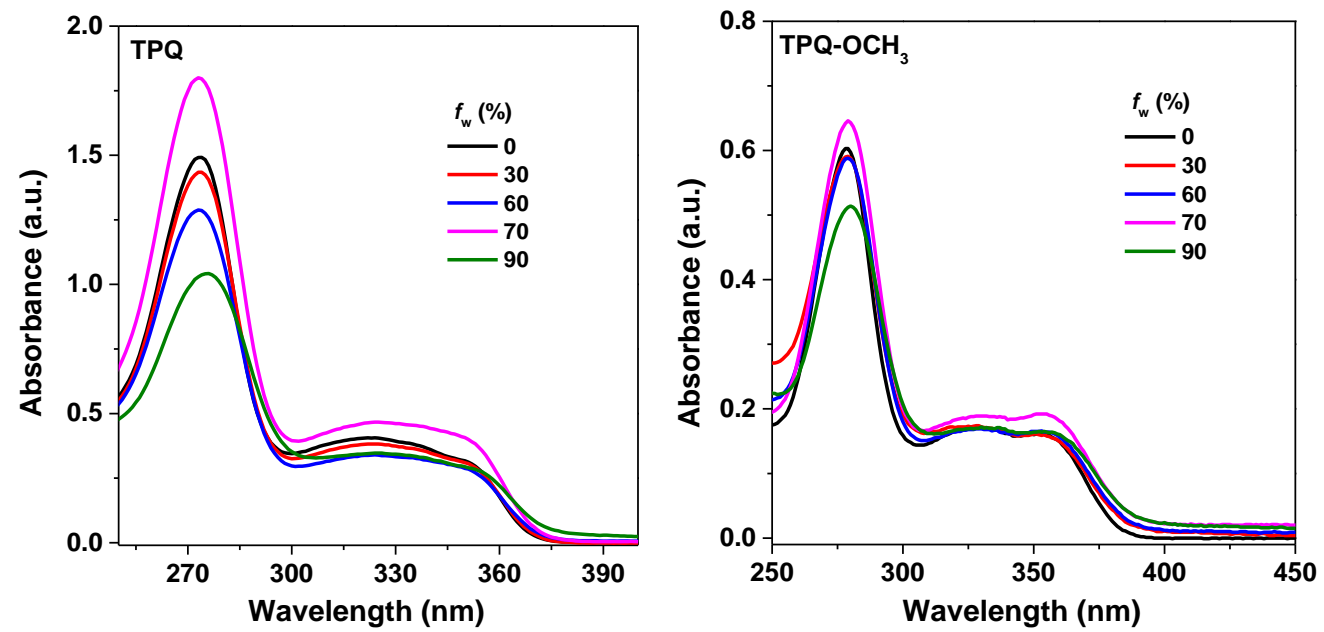

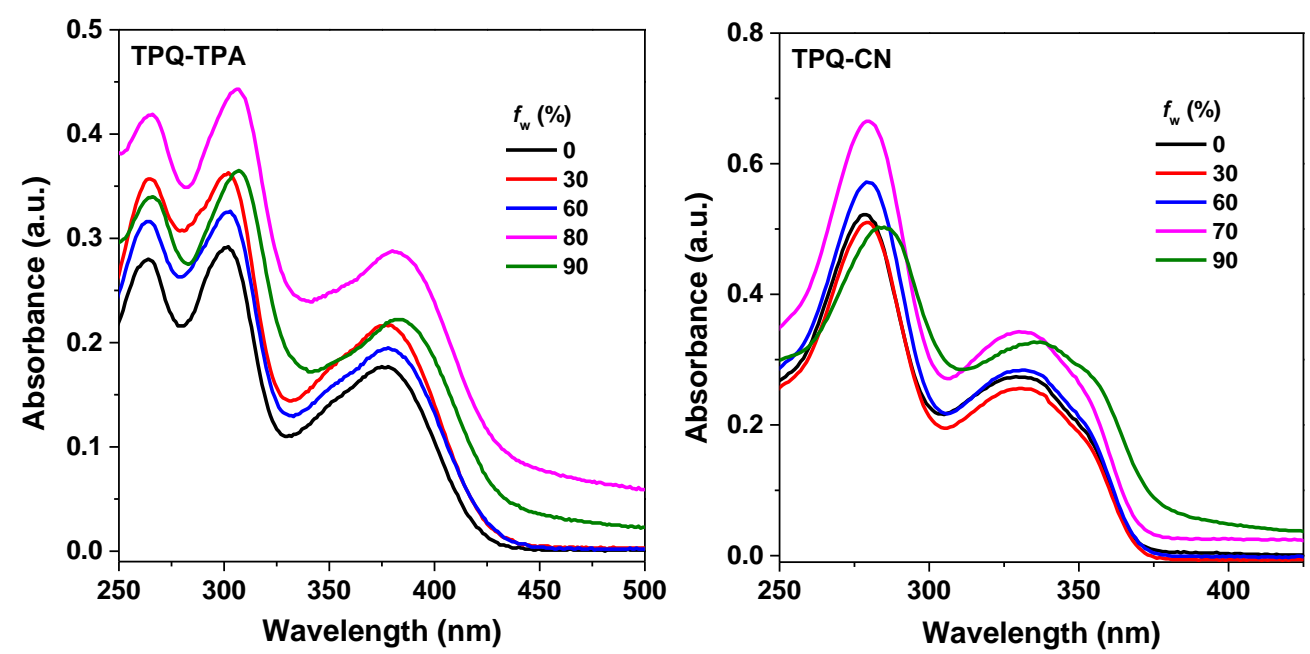

Figure S4. UV-Vis absorption spectra of TPQ derivatives in THF/water mixtures with different water volume fractions. (Concentration: $1 \times 10^{-5} \mathrm{~mol} / \mathrm{L}$ ).
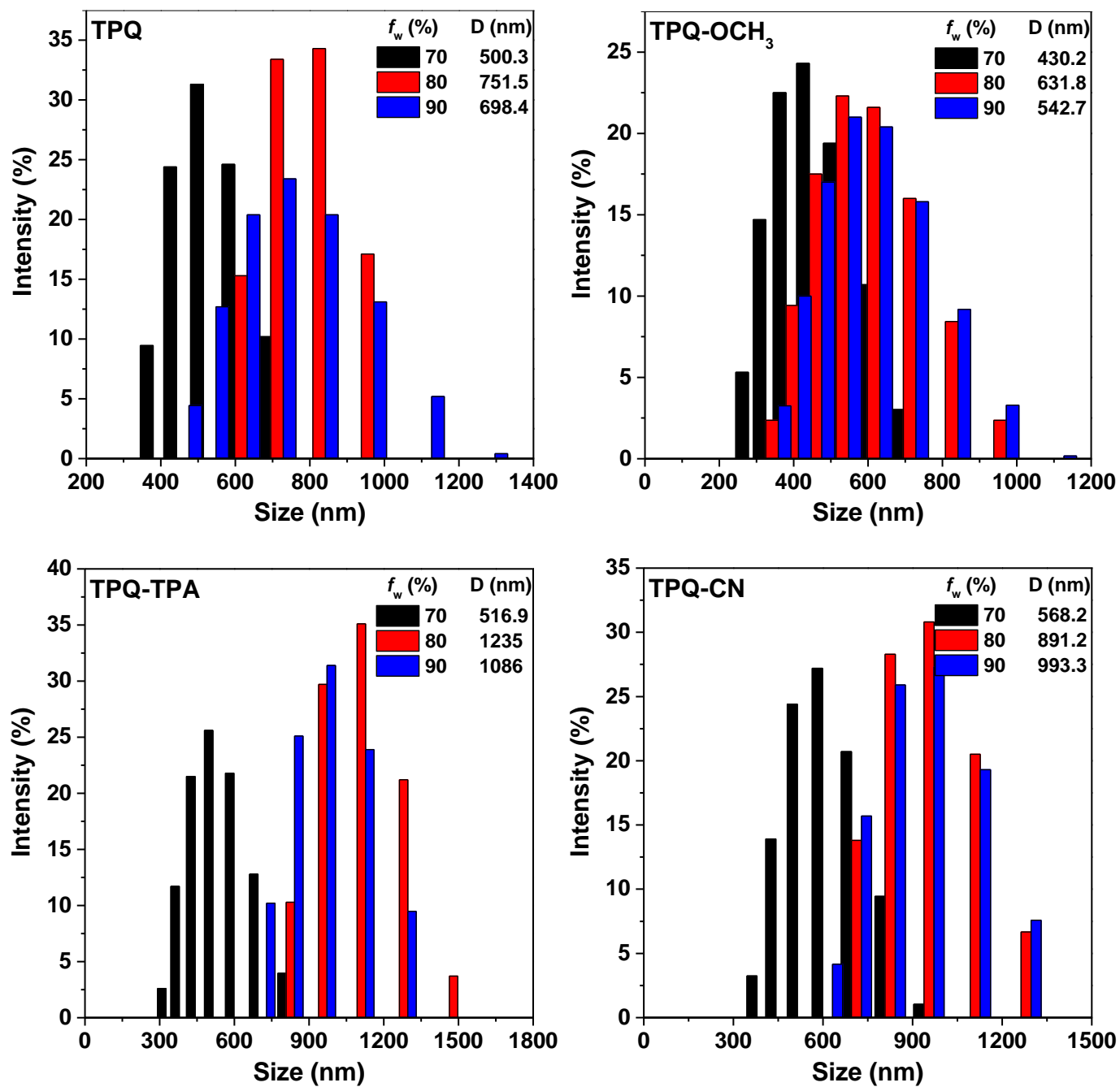

Figure S5. DLS of TPQ derivatives in THF/water mixtures with different water volume fractions. (Concentration: $1 \times 10^{-5} \mathrm{~mol} / \mathrm{L}$ ). 
Table S1. The lifetime and Quantum Yield of TPQ derivatives in solution and in solid.

\begin{tabular}{|c|c|c|c|c|c|c|c|c|}
\hline \multirow[t]{2}{*}{ Compounds } & \multicolumn{2}{|c|}{$\begin{array}{l}\text { Lifetime } \\
\tau(\mathrm{ns})\end{array}$} & \multicolumn{2}{|c|}{$\begin{array}{c}\text { Quantum Yield } \\
\Phi(\%)\end{array}$} & \multicolumn{2}{|c|}{$\begin{array}{l}\text { Radiative Rate } \\
k_{\mathrm{r}} \times 10^{8}\left(\mathrm{~s}^{-1}\right)\end{array}$} & \multicolumn{2}{|c|}{$\begin{array}{l}\text { Nonradiative Rate } \\
\qquad k_{\mathrm{nr}} \times 10^{8}\left(\mathrm{~s}^{-1}\right)\end{array}$} \\
\hline & Solution & Solid & Solution & Solid & Solution & Solid & Solution & Solid \\
\hline TPQ & 0.89 & 0.83 & 25 & 11 & 2.809 & 1.325 & 8.427 & 10.72 \\
\hline $\mathrm{TPQ}^{-\mathrm{OCH}_{3}}$ & 2.41 & 1.65 & 56 & 30 & 2.324 & 1.818 & 1.826 & 4.242 \\
\hline TPQ-TPA & 5.32 & 4.24 & 70 & 48 & 1.316 & 1.132 & 0.564 & 1.226 \\
\hline TPQ-CN & 0.36 & 1.31 & 13 & 28 & 3.611 & 2.137 & 24.17 & 5.496 \\
\hline
\end{tabular}

The radiative decay rate $k_{\mathrm{r}}=\Phi_{\mathrm{F}} / \tau$. The nonradiative decay rate $k_{\mathrm{nr}}=1 / \tau-k_{\mathrm{r}}$.
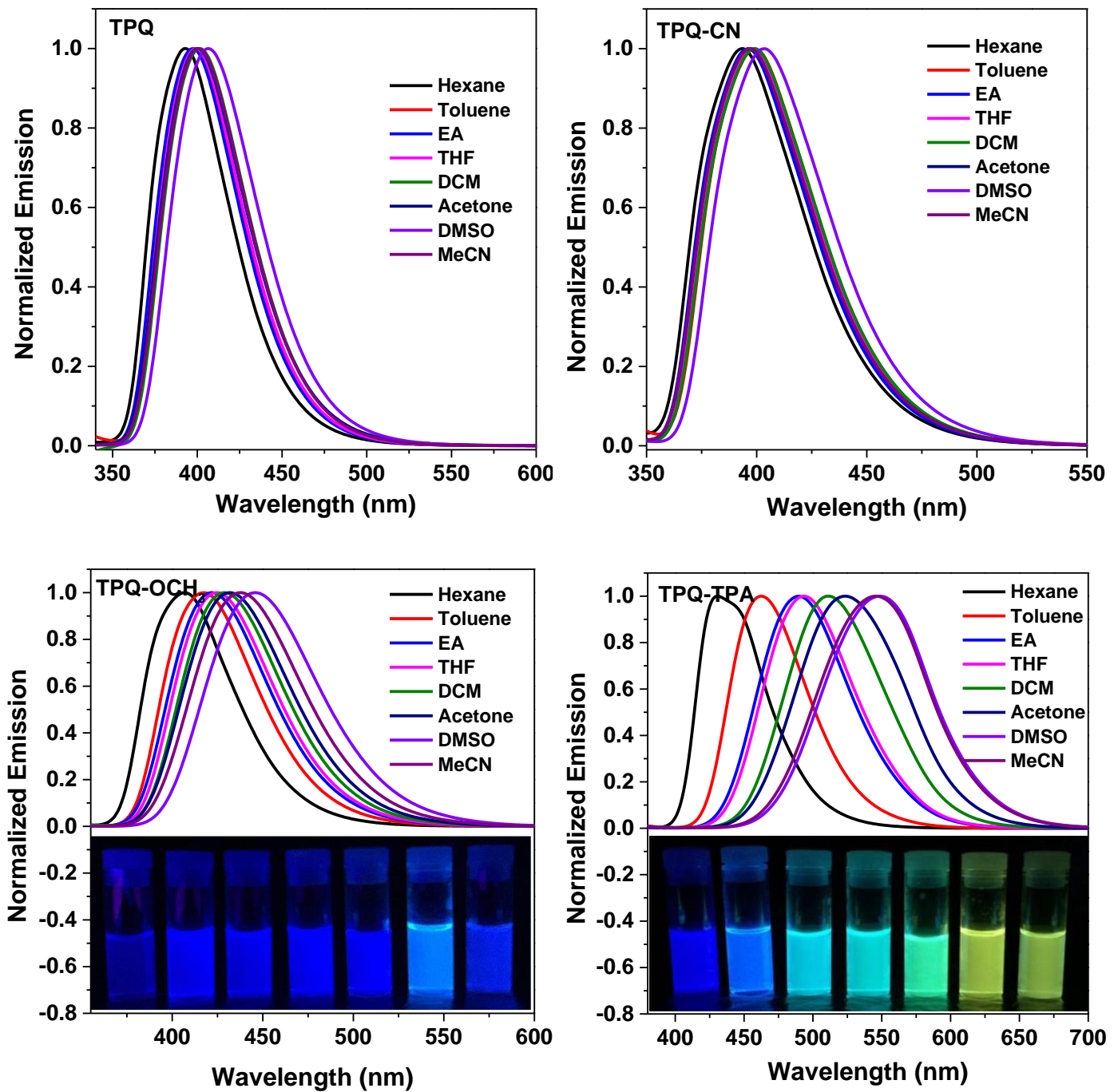

Figure S6. Fluorescence spectra of derivatives in various solvents. (Concentration: $\left.1 \times 10^{-5} \mathrm{~mol} / \mathrm{L}\right)$. Inset picture: their photographs in solution $(1$ $\times 10^{-5} \mathrm{~mol} / \mathrm{L}$, from left to right: hexane, toluene, EA, THF, DCM, Acetone, DMSO and MeCN) taken under 365-nm UV illumination. 

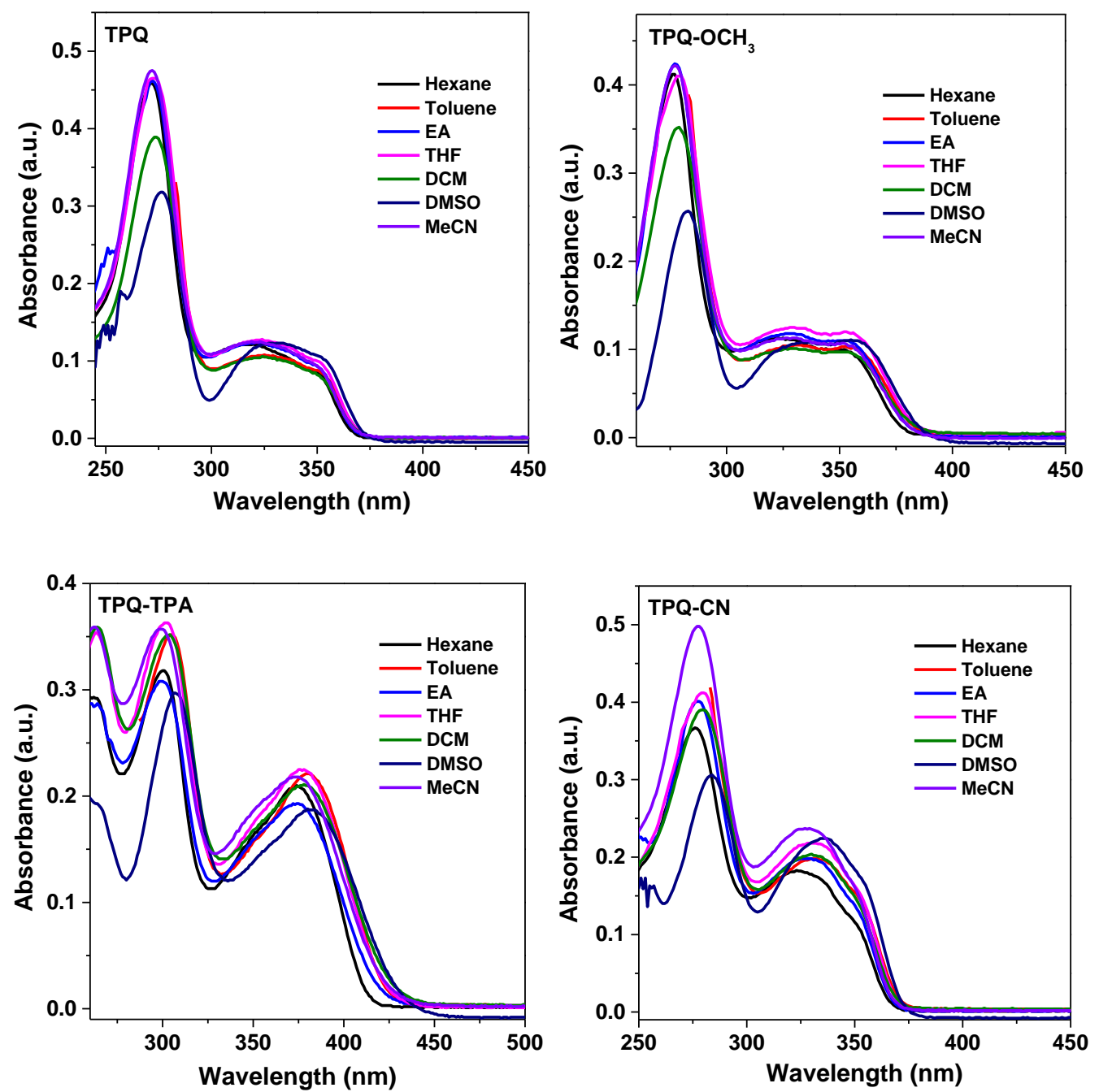

Figure S7. UV-Vis absorption spectra of TPQ derivatives in various solvents. (Concentration: $1 \times 10^{-5} \mathrm{~mol} / \mathrm{L}$ ).

Table S2. The absorption band maxima ( $\left.v_{\mathrm{abs}}\right)$, luminescence maxima $\left(v_{\mathrm{em}}\right)$, Stokes shifts $(\Delta v)$, solvent polarity parameter $(\Delta f)$ obtained at R.T. for TPQ derivatives, dissolved in 7 typical organic solvents.

\begin{tabular}{|c|c|c|c|c|c|c|c|}
\hline Solvent & $\Delta f$ & $\begin{array}{c}v_{\mathrm{ab}} \\
\mathbf{T P Q} \\
\left(\mathrm{cm}^{-1}\right)\end{array}$ & $\begin{array}{c}v \text { em } \\
\text { TPQ } \\
\left(\mathrm{cm}^{-1}\right)\end{array}$ & $\begin{array}{c}\Delta v \\
\text { TPQ } \\
/ 10^{3}\left(\mathrm{~cm}^{-1}\right)\end{array}$ & $\begin{array}{c}v \mathrm{ab} \\
\mathbf{T P Q}-\mathbf{C N} \\
\left(\mathrm{cm}^{-1}\right)\end{array}$ & $\begin{array}{c}v \text { em } \\
\text { TPQ-CN } \\
\left(\mathrm{cm}^{-1}\right)\end{array}$ & $\begin{array}{c}\Delta v \\
\mathbf{T P Q}-\mathbf{C N} \\
/ 10^{3}\left(\mathrm{~cm}^{-1}\right)\end{array}$ \\
\hline Hexane & 0 & 31250 & 25445 & 5.805 & 30960 & 25419 & 5.541 \\
\hline Toluene & 0.0135 & 30769 & 25063 & 5.706 & 30030 & 25050 & 4.980 \\
\hline EA & 0.201 & 30959 & 25189 & 5.770 & 30303 & 25252 & 5.051 \\
\hline THF & 0.2096 & 30864 & 25063 & 5.801 & 30120 & 25113 & 5.007 \\
\hline $\mathrm{DCM}$ & 0.2184 & 30864 & 24938 & 5.926 & 30303 & 25063 & 5.051 \\
\hline
\end{tabular}




\begin{tabular}{|c|c|c|c|c|c|c|c|}
\hline DMSO & 0.263 & 30581 & 24630 & 5.951 & 29674 & 24789 & 4.885 \\
\hline $\mathrm{CH}_{3} \mathrm{CN}$ & 0.305 & 30959 & 24938 & 6.021 & 30303 & 25202 & 5.051 \\
\hline Solvent & $\Delta f$ & $\begin{array}{c}v_{\mathrm{ab}} \\
\mathbf{T P Q} \mathbf{O C H}_{3} \\
\left(\mathrm{~cm}^{-1}\right)\end{array}$ & $\begin{array}{c}v \text { em } \\
\text { TPQ-OCH } \\
\left(\mathrm{cm}^{-1}\right)\end{array}$ & $\begin{array}{c}\Delta v \\
\text { TPQ-OCH } \\
/ 10^{3}\left(\mathrm{~cm}^{-1}\right)\end{array}$ & $\begin{array}{c}v \text { ab } \\
\text { TPQ- } \\
\text { TPA } \\
\left(\mathrm{cm}^{-1}\right) \\
\end{array}$ & $\begin{array}{c}v \text { em } \\
\text { TPQ-TPA } \\
\left(\mathrm{cm}^{-1}\right)\end{array}$ & $\begin{array}{c}\Delta v \\
\text { TPQ-TPA } \\
/ 10^{3}\left(\mathrm{~cm}^{-1}\right)\end{array}$ \\
\hline Hexane & 0 & 30769 & 24582 & 6.187 & 26738 & 23213 & 3.525 \\
\hline Toluene & 0.0135 & 30120 & 23958 & 6.162 & 26247 & 21626 & 4.621 \\
\hline EA & 0.201 & 30488 & 23696 & 6.792 & 26667 & 20416 & 6.251 \\
\hline $\mathrm{THF}$ & 0.2096 & 30395 & 23552 & 6.843 & 26455 & 20268 & 6.187 \\
\hline DCM & 0.2184 & 30395 & 23321 & 7.074 & 26455 & 19562 & 6.893 \\
\hline DMSO & 0.263 & 29762 & 22442 & 7.320 & 26316 & 18228 & 8.088 \\
\hline $\mathrm{CH}_{3} \mathrm{CN}$ & 0.305 & 30395 & 22852 & 7.543 & 26667 & 18328 & 8.339 \\
\hline
\end{tabular}
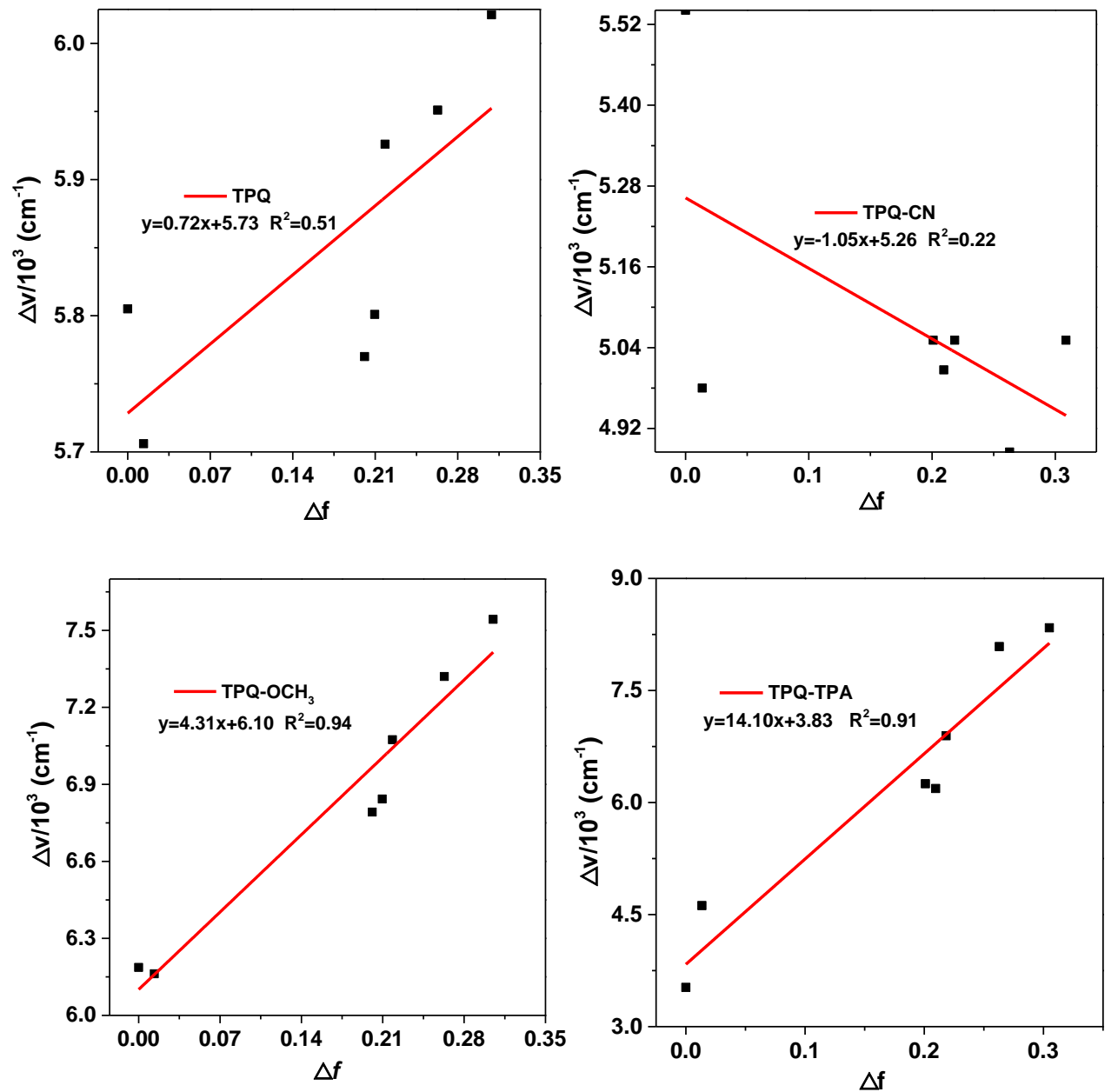

Figure S8. Plot of Stokes shift $(\Delta v)$ of TPQ derivatives versus $\Delta f$ of their solutions. (Hexane, Toluene, EA, THF, DCM, DMSO, $\mathrm{CH}_{3} \mathrm{CN}$ ). 

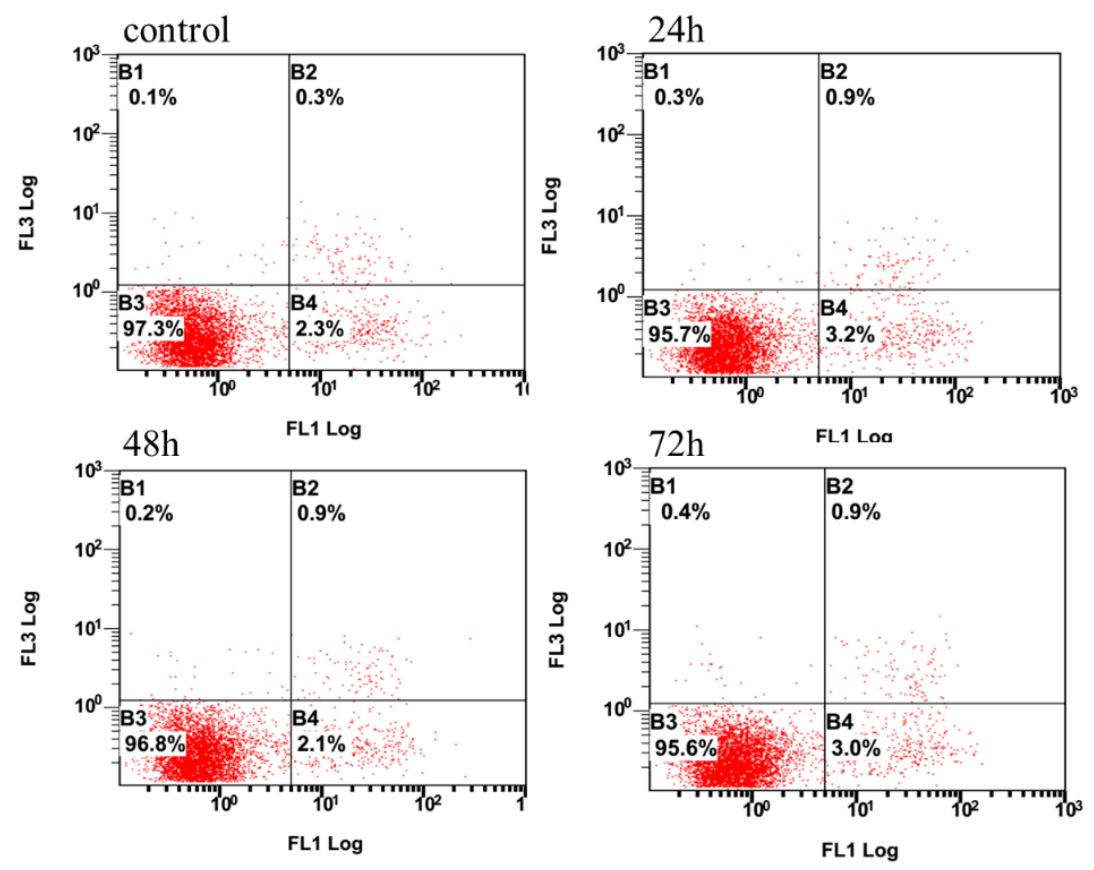

Figure S9. The apoptosis assay of TPQ-TPA evaluated on HeLa cells. (Concentration: $1 \times 10^{-5} \mathrm{~mol} / \mathrm{L}$ ).

\section{Mass spectra and NMR spectra:}

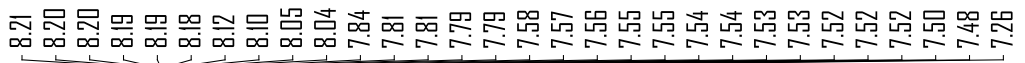<smiles>Brc1ccc2nc(-c3ccccc3)cc(-c3ccccc3)c2c1</smiles>

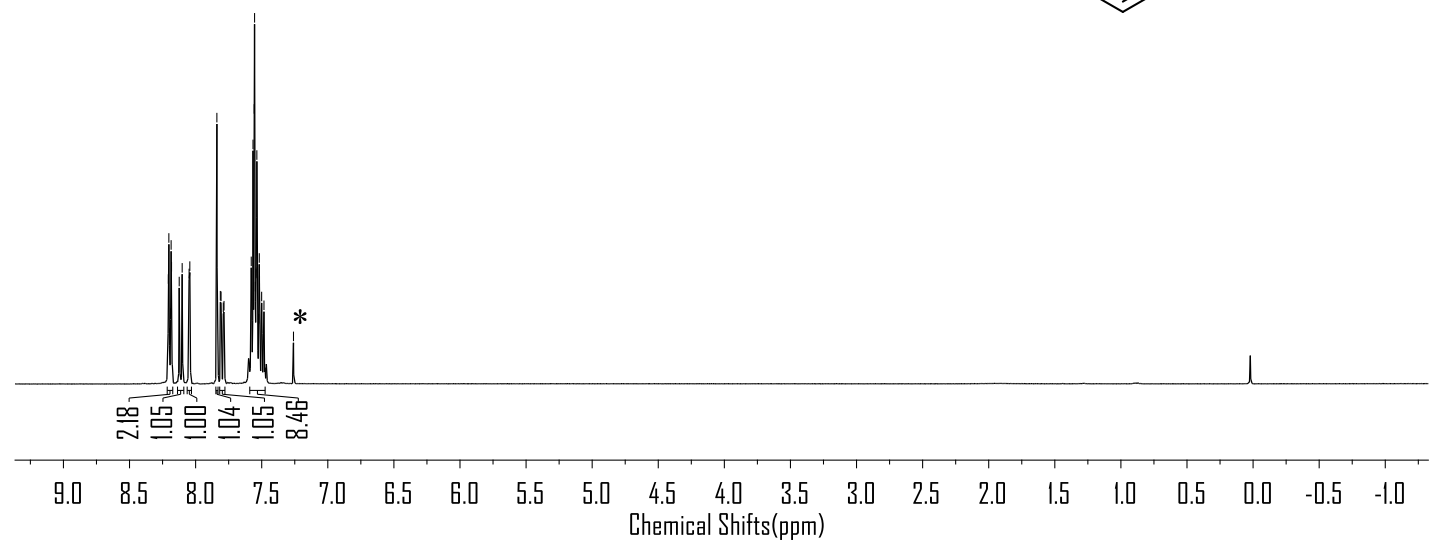

Figure S10. The ${ }^{1} \mathrm{H}$ NMR spectrum of 4 in $\mathrm{CDCl}_{3}, 298 \mathrm{~K}$. 


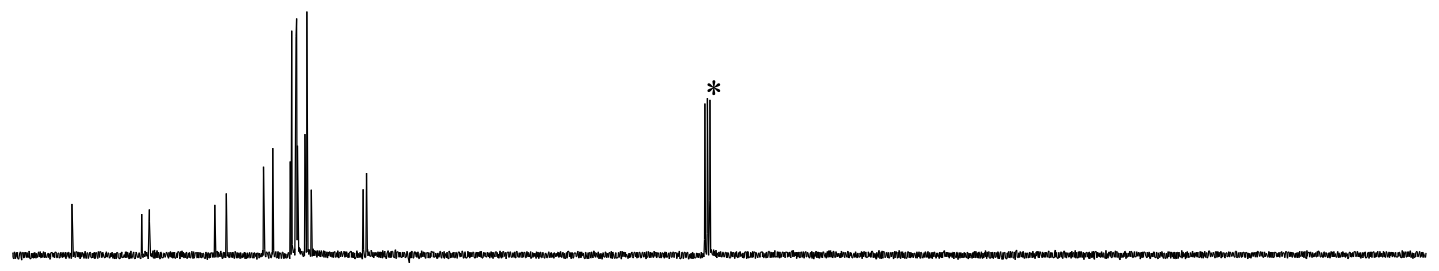

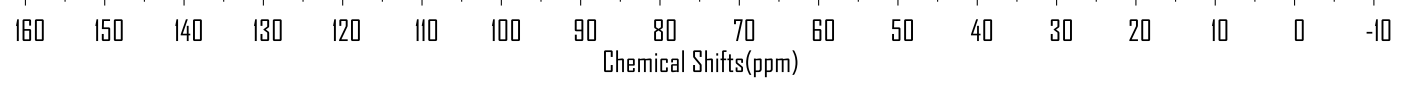

Figure S11. The ${ }^{13} \mathrm{C}$ NMR spectrum of 4 in $\mathrm{CDCl}_{3}, 298 \mathrm{~K}$.

LWB-0728

$2018073001272(4.534) \mathrm{Cm}(272-(116+326))$

100

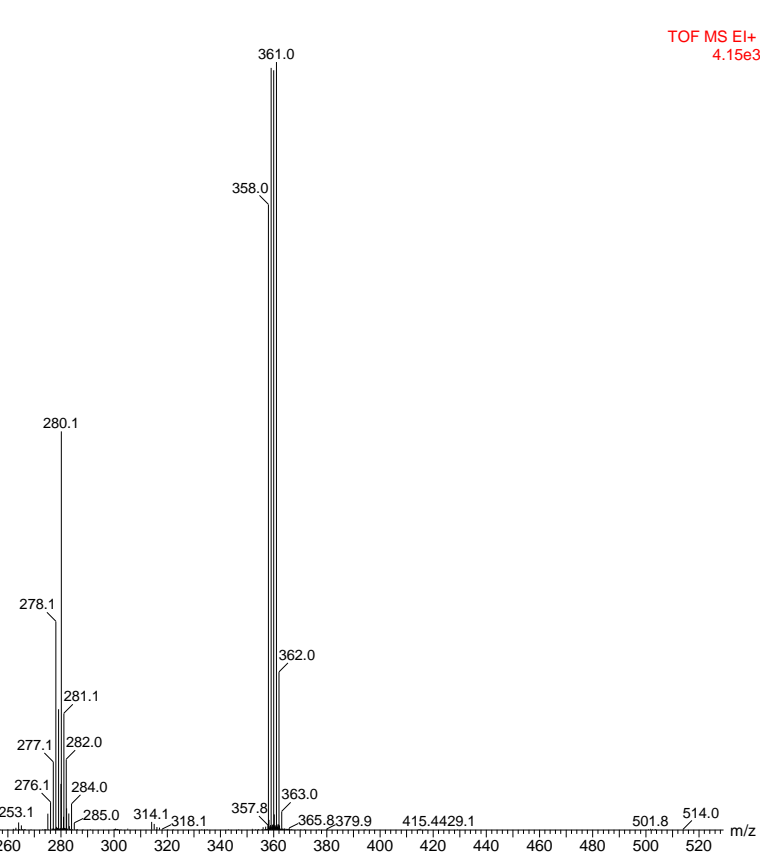

Figure S12. The Mass Spectrum of 4. 

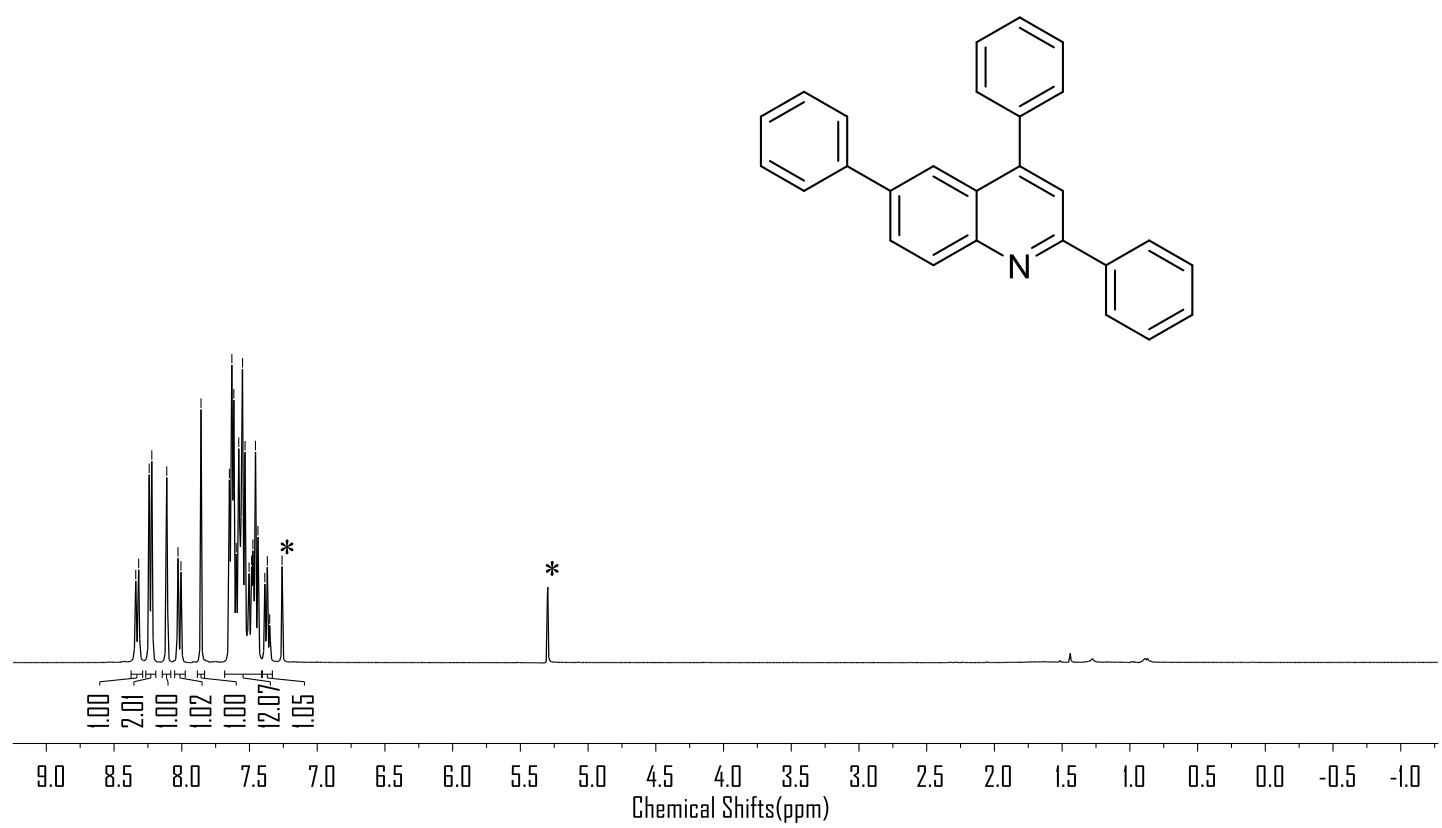

Figure S13. The ${ }^{1} \mathrm{H}$ NMR spectrum of TPQ in $\mathrm{CDCl}_{3}, 298 \mathrm{~K}$.

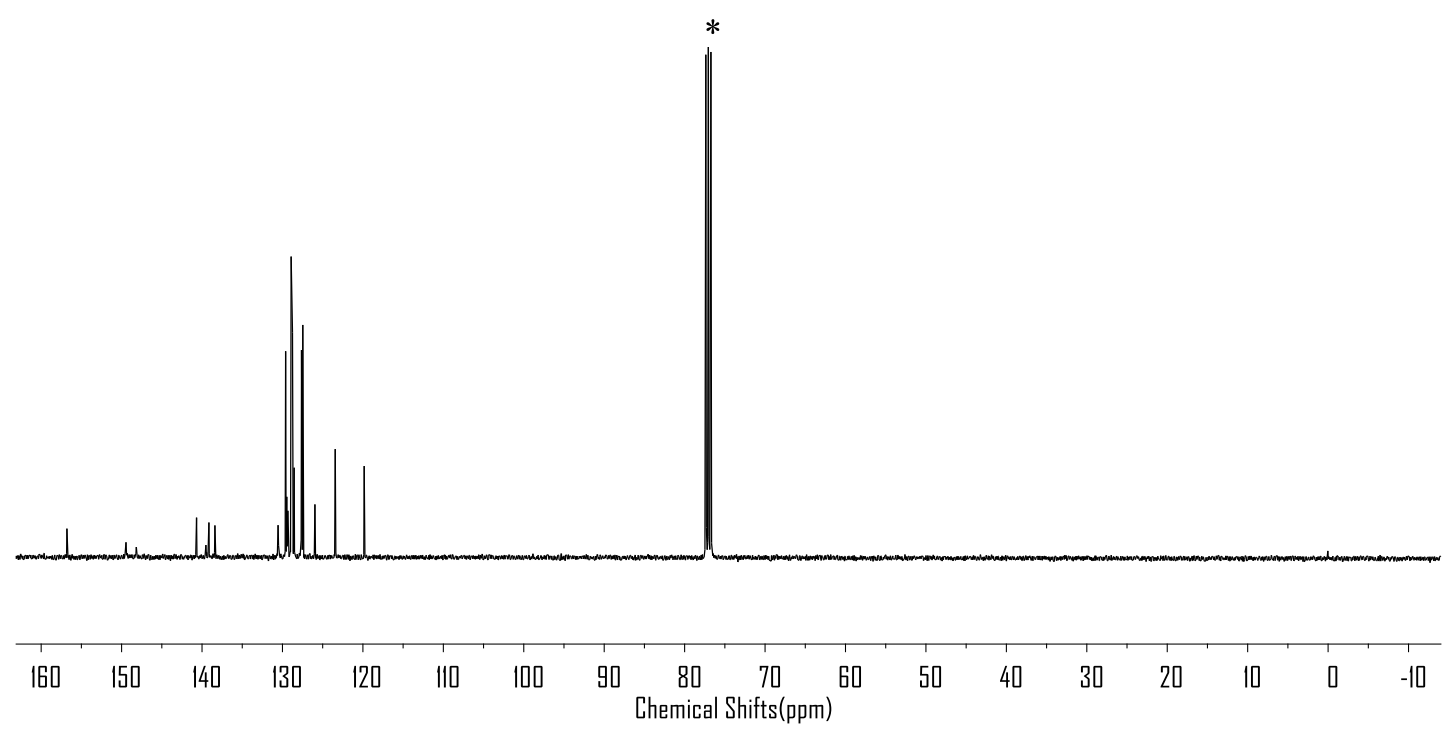

Figure S14. The ${ }^{13} \mathrm{C}$ NMR spectrum of TPQ in $\mathrm{CDCl}_{3}, 298 \mathrm{~K}$. 


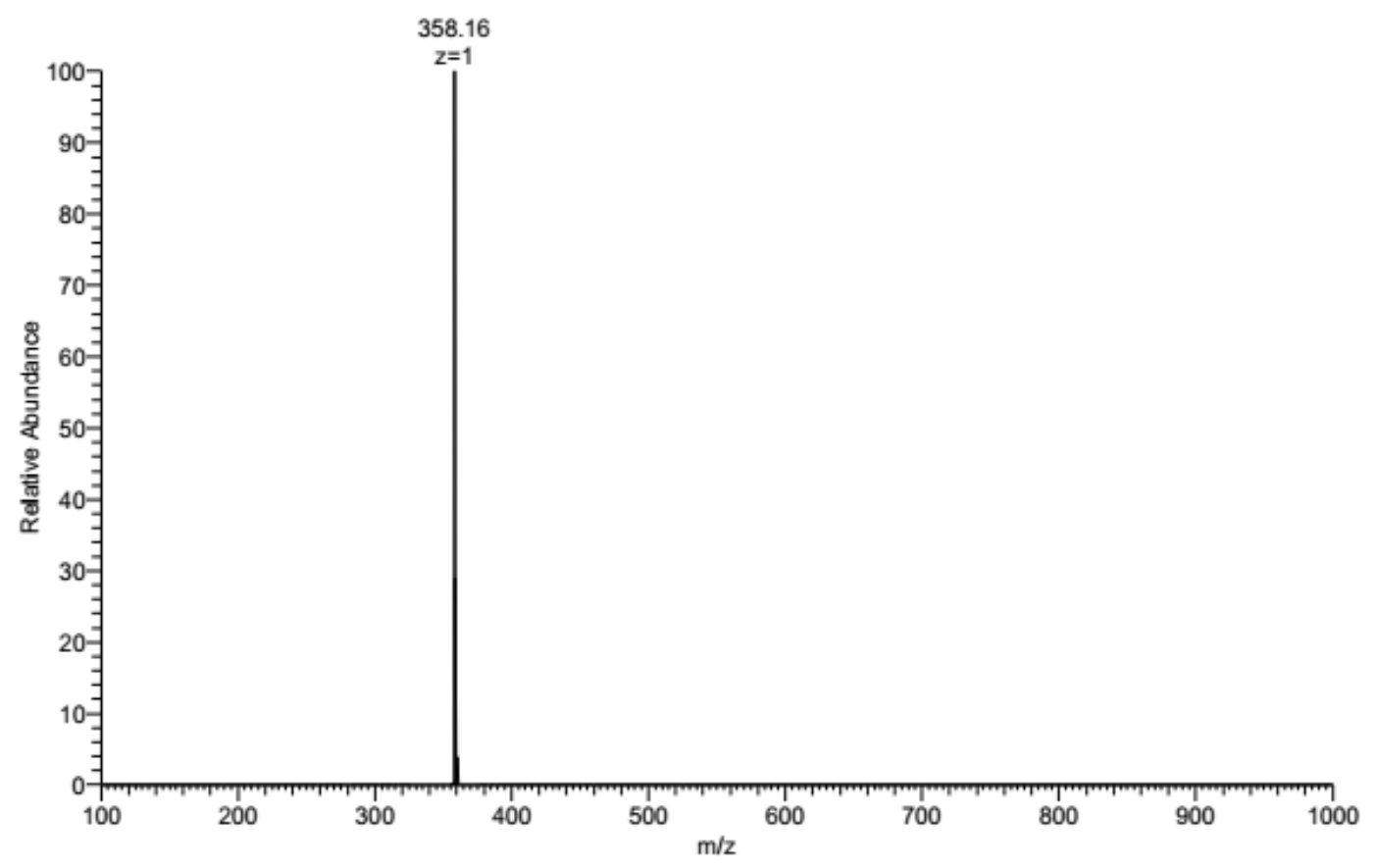

Figure S15. The Mass Spectrum of TPQ.

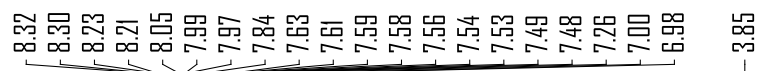

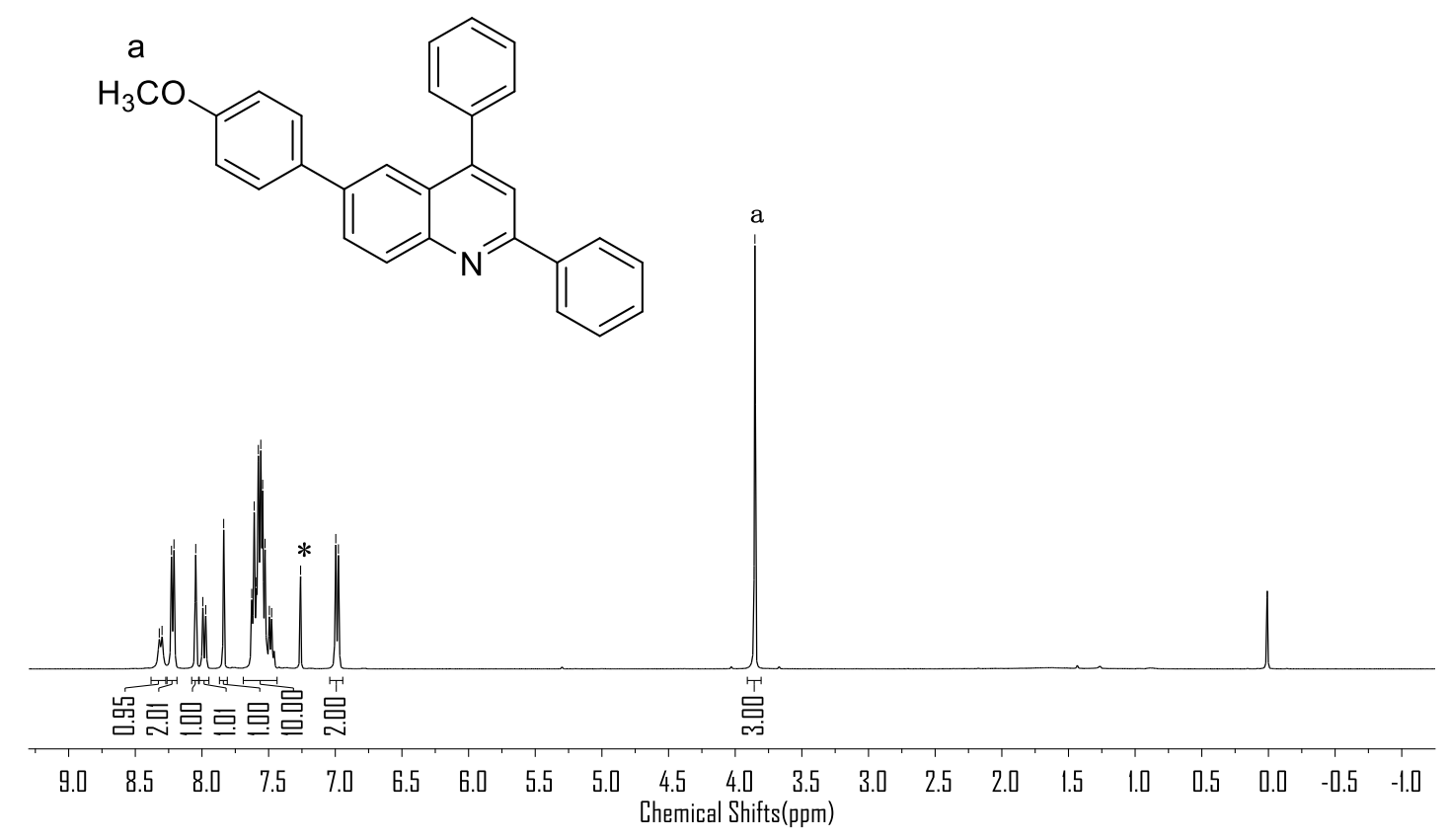

Figure S16. The ${ }^{1} \mathrm{H}$ NMR spectrum of TPQ- $\mathbf{O C H}$ in $\mathrm{CDCl}_{3}, 298 \mathrm{~K}$. 


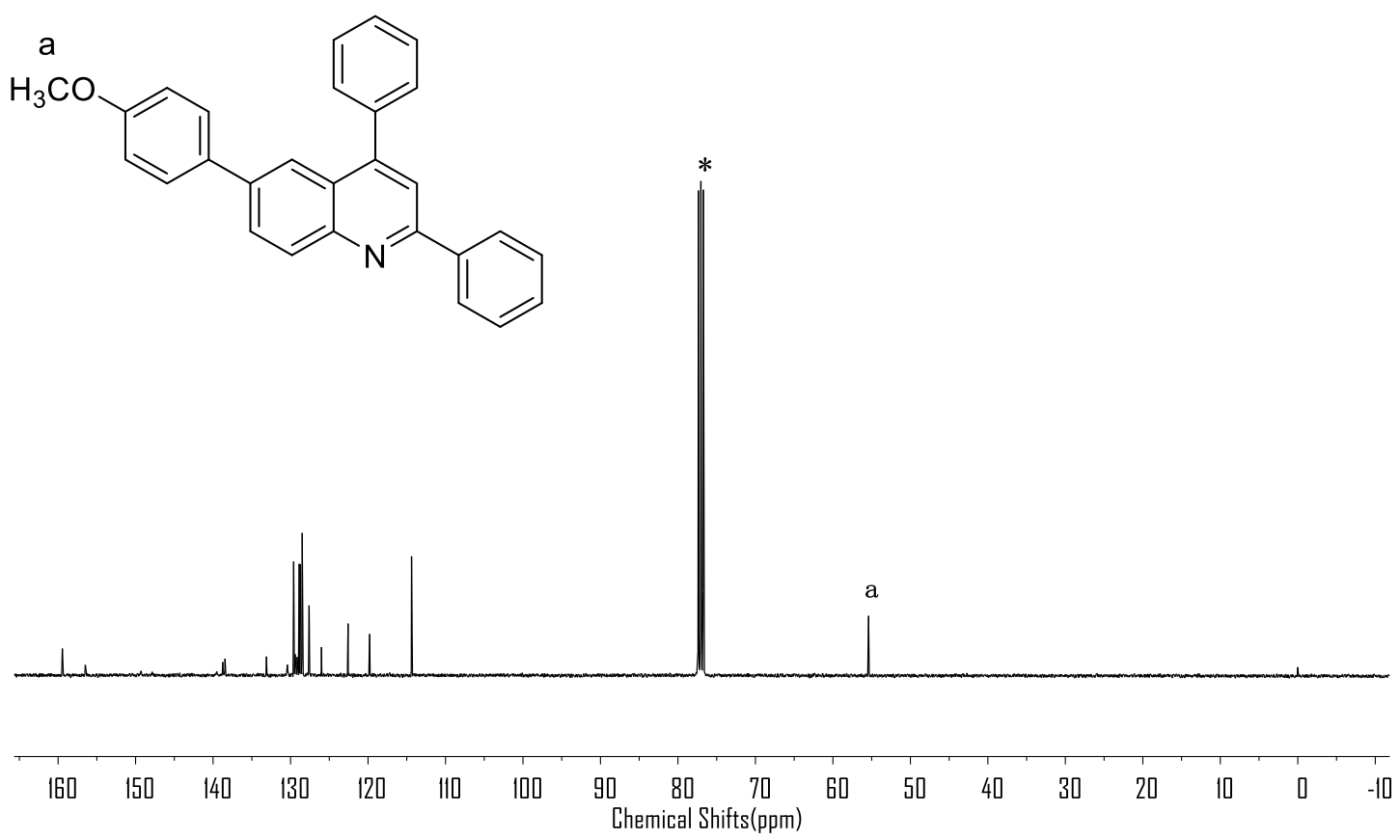

Figure S17. The ${ }^{13} \mathrm{C}$ NMR spectrum of TPQ-OCH 3 in $\mathrm{CDCl}_{3}, 298 \mathrm{~K}$.

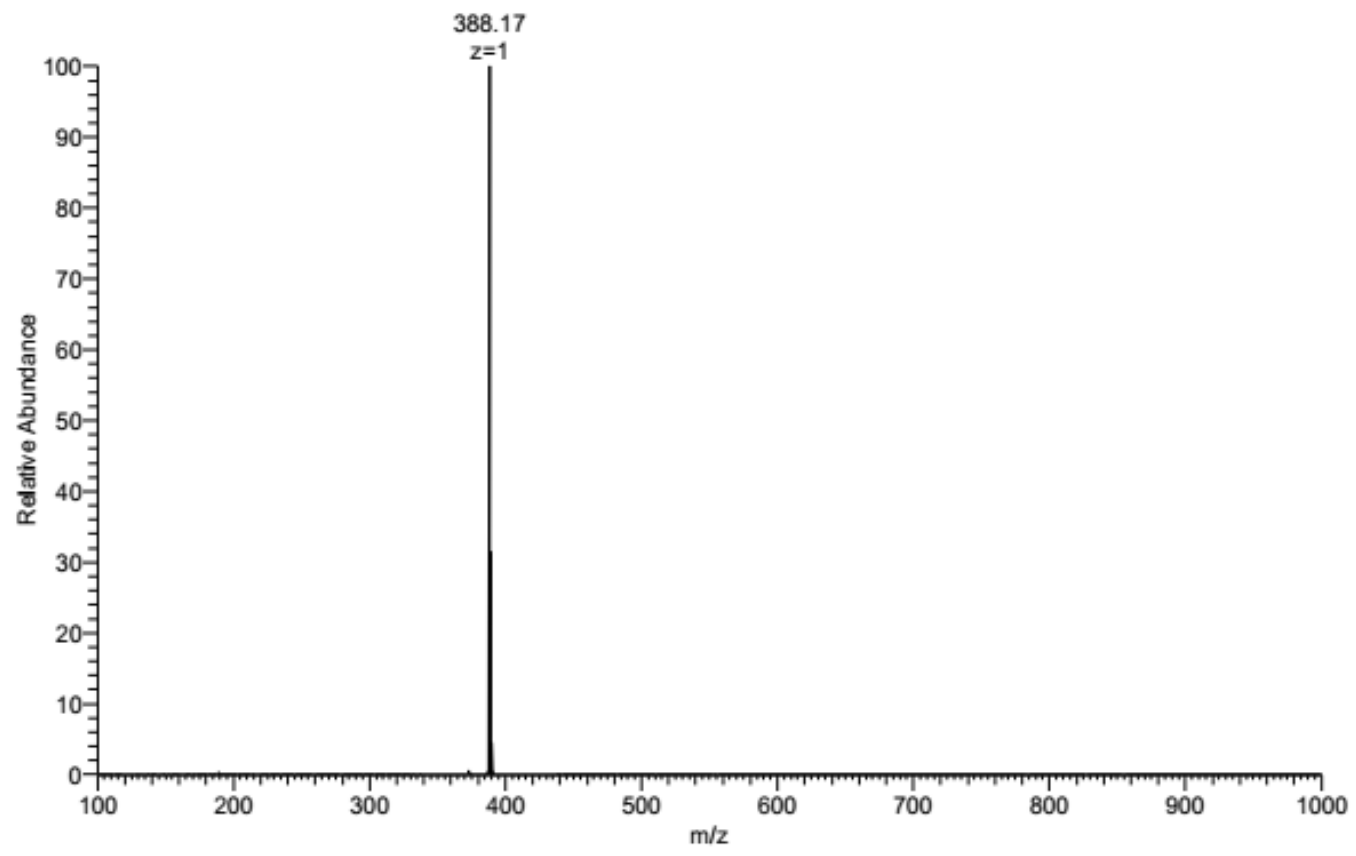

Figure S18. The Mass Spectrum of TPQ-OCH $\mathbf{H}_{3}$ 

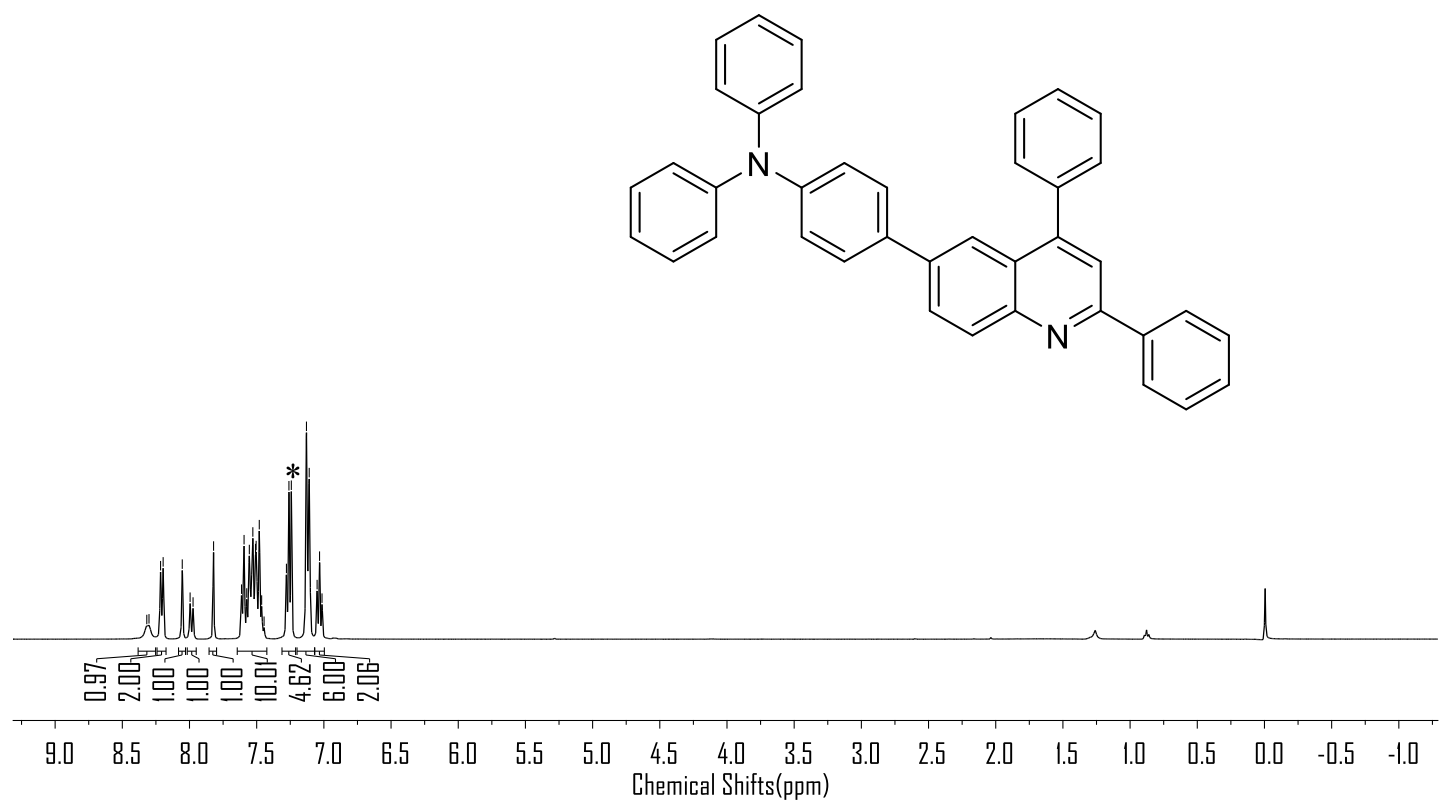

Figure S19. The ${ }^{1} \mathrm{H}$ NMR spectrum of TPQ-TPA in $\mathrm{CDCl}_{3}, 298 \mathrm{~K}$.

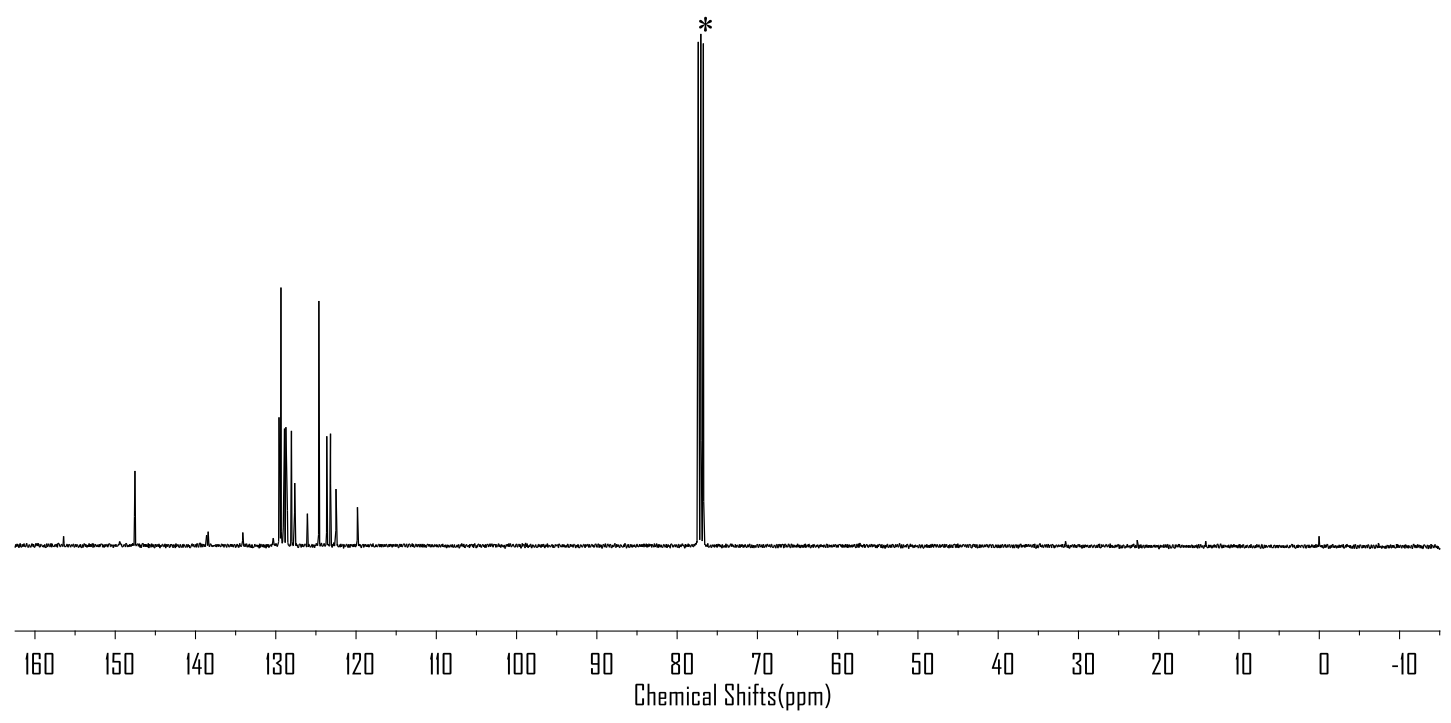

Figure S20. The ${ }^{13} \mathrm{C}$ NMR spectrum of TPQ-TPA in $\mathrm{CDCl}_{3}, 298 \mathrm{~K}$. 


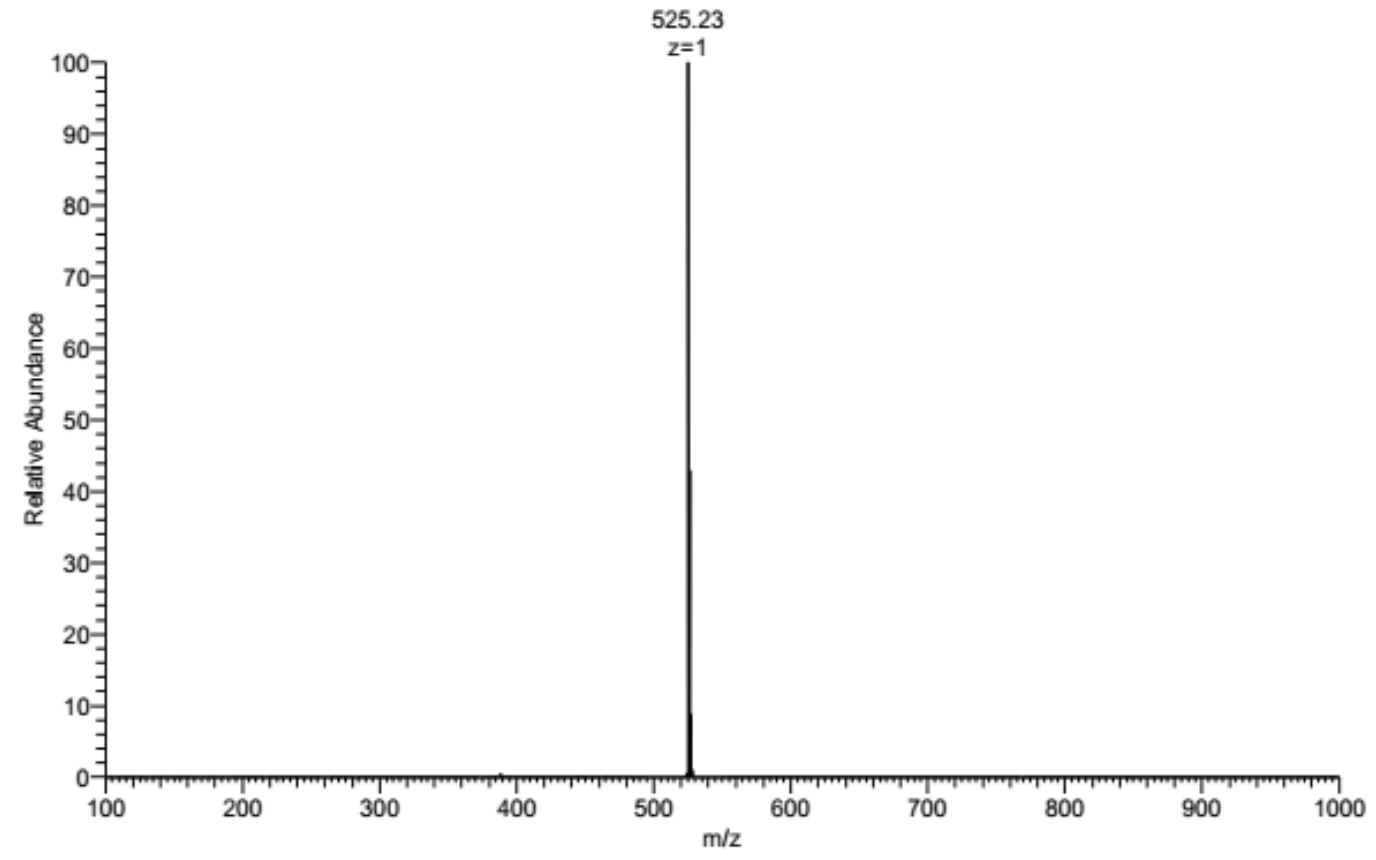

Figure S21. The Mass Spectrum of TPQ-TPA.

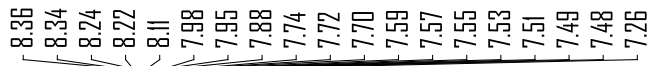
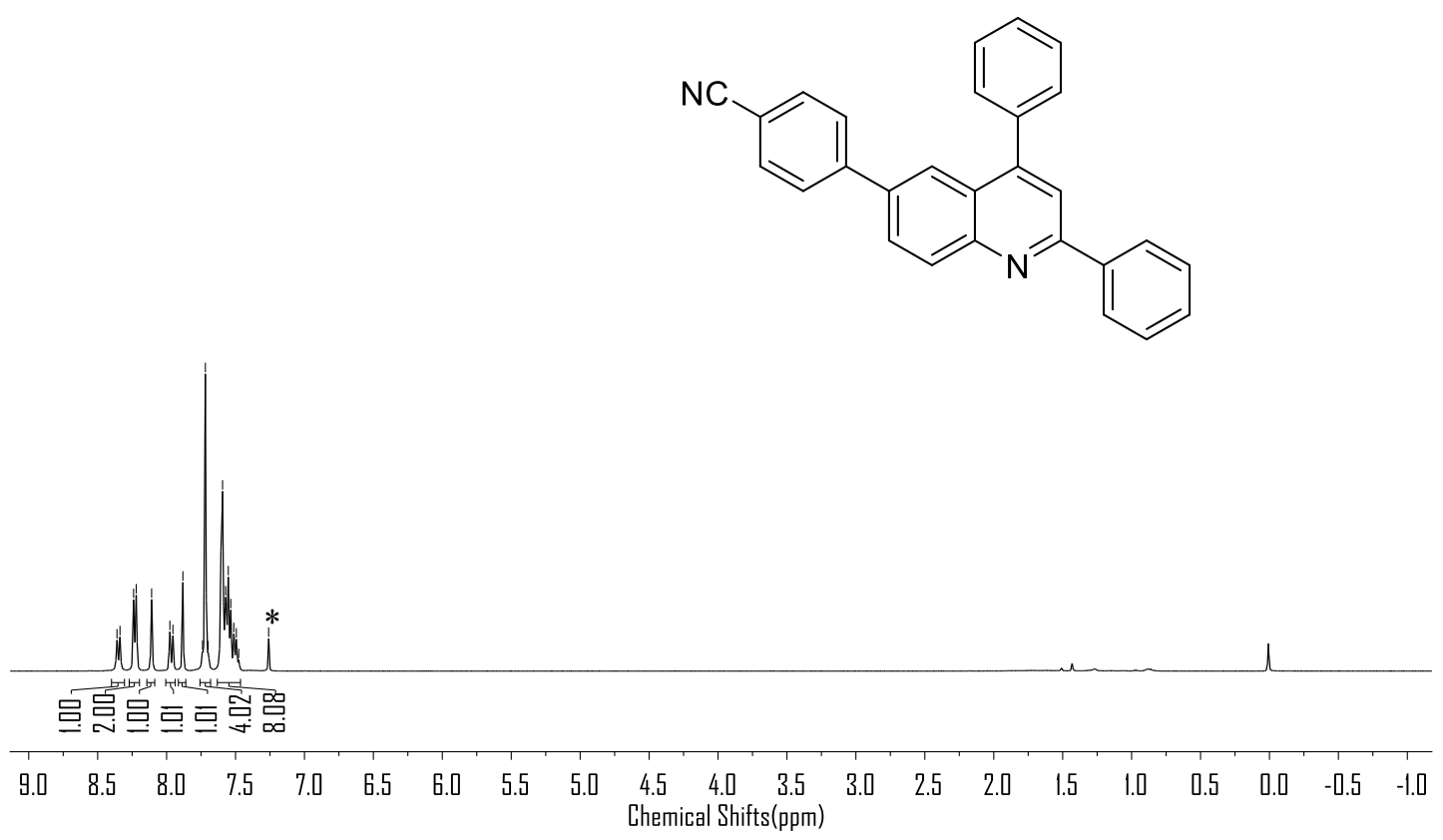

Figure S22. The ${ }^{1} \mathrm{H}$ NMR spectrum of TPQ-CN in $\mathrm{CDCl}_{3}, 298 \mathrm{~K}$. 


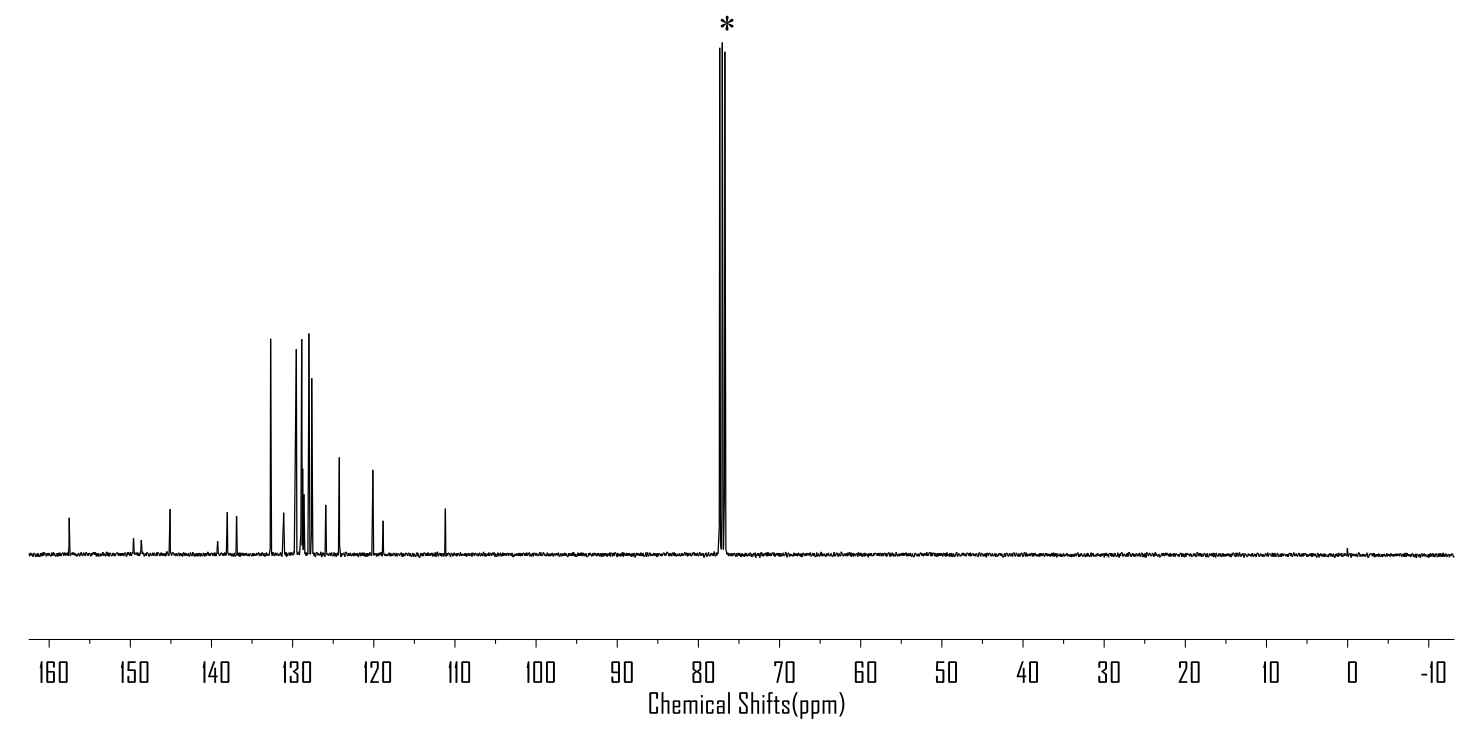

Figure S23. The ${ }^{13} \mathrm{C}$ NMR spectrum of TPQ-CN in $\mathrm{CDCl}_{3}, 298 \mathrm{~K}$.

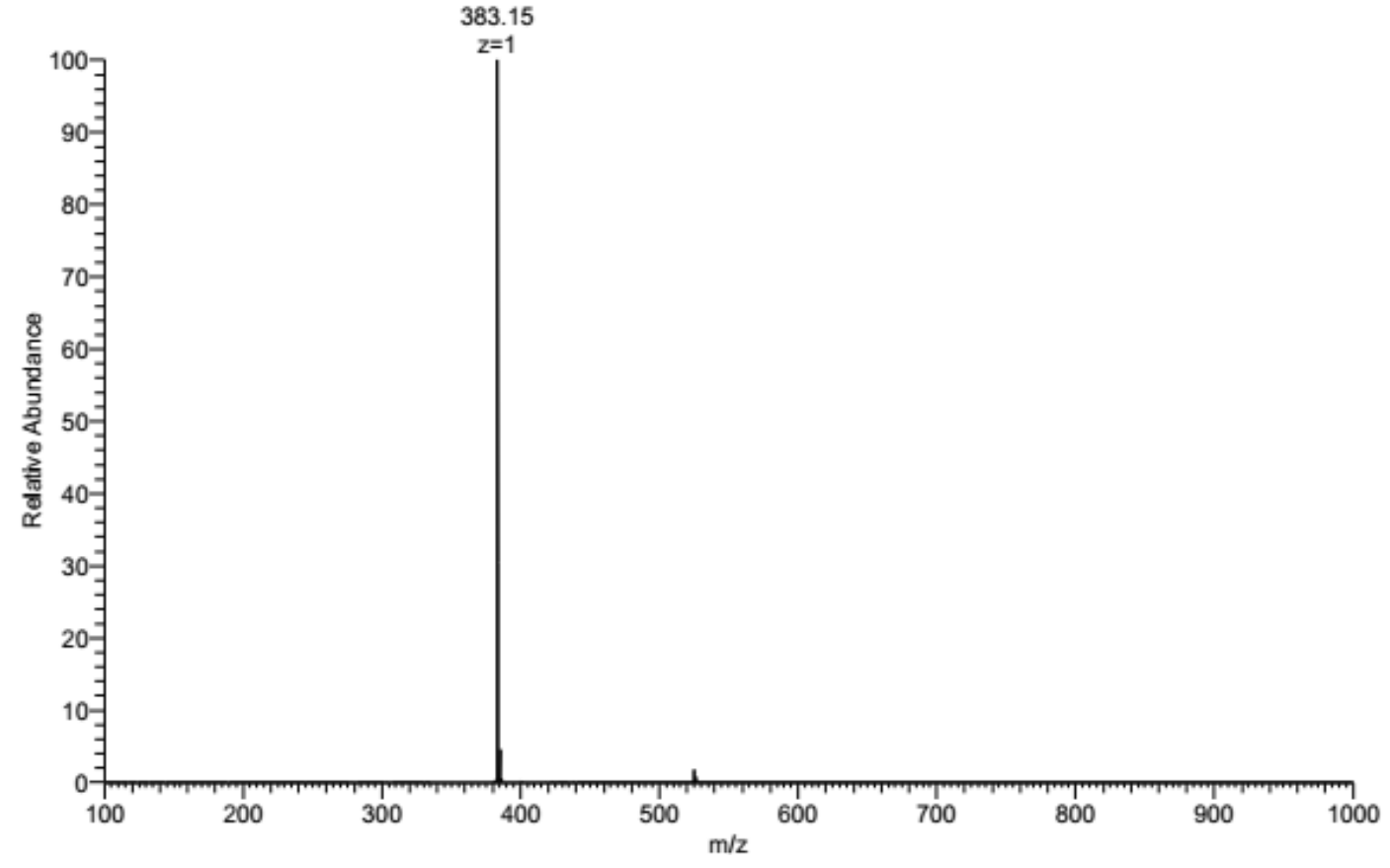

Figure S24. The Mass Spectrum of TPQ-CN.

Table S3. Crystal data and structure refinement for TPQ.

Empirical formula

Formula weight

Temperature/K

Crystal system

Space group
$\mathrm{C}_{27} \mathrm{H}_{19} \mathrm{~N}$

357.43

153.15

triclinic

P-1 


\begin{tabular}{|c|c|}
\hline $\mathrm{a} / \AA$ & $11.010(2)$ \\
\hline $\mathrm{b} / \AA$ & $13.226(3)$ \\
\hline$c / \AA$ & $13.251(3)$ \\
\hline$\alpha /^{\circ}$ & $90.60(3)$ \\
\hline$\beta /{ }^{\circ}$ & $101.63(3)$ \\
\hline$\gamma /{ }^{\circ}$ & $92.88(3)$ \\
\hline Volume $/ \AA^{3}$ & 1887.1(7) \\
\hline $\mathrm{Z}$ & 4 \\
\hline$\rho_{\text {calc }} g / \mathrm{cm}^{3}$ & 1.258 \\
\hline$\mu / \mathrm{mm}^{-1}$ & 0.072 \\
\hline $\mathrm{F}(000)$ & 752.0 \\
\hline Crystal size $/ \mathrm{mm}^{3}$ & $0.13 \times 0.12 \times 0.1$ \\
\hline Radiation & $\operatorname{MoK} \alpha(\lambda=0.71073)$ \\
\hline $2 \Theta$ range for data collection ${ }^{\circ}$ & 3.138 to 49.998 \\
\hline Index ranges & $-13 \leq \mathrm{h} \leq 13,-15 \leq \mathrm{k} \leq 15,-13 \leq 1 \leq 15$ \\
\hline Reflections collected & 15656 \\
\hline Independent reflections & $6573\left[\mathrm{R}_{\mathrm{int}}=0.0325, \mathrm{R}_{\mathrm{sigma}}=0.0420\right]$ \\
\hline Data/restraints/parameters & $6573 / 0 / 505$ \\
\hline Goodness-of-fit on $\mathrm{F}^{2}$ & 1.129 \\
\hline Final $R$ indexes $[I>=2 \sigma(I)]$ & $\mathrm{R}_{1}=0.0944, \mathrm{wR}_{2}=0.1857$ \\
\hline Final $\mathrm{R}$ indexes [all data] & $\mathrm{R}_{1}=0.1037, \mathrm{wR}_{2}=0.1928$ \\
\hline Largest diff. peak/hole / e $\AA^{-3}$ & $0.76 /-0.31$ \\
\hline
\end{tabular}

Table S4. Crystal data and structure refinement for TPQ-OCH .

\begin{tabular}{ll}
\hline Empirical formula & $\mathrm{C}_{28} \mathrm{H}_{21} \mathrm{NO}$ \\
\hline Formula weight & 387.46 \\
Temperature/K & 153.15 \\
Crystal system & triclinic \\
Space group & $\mathrm{P}-1$ \\
$\mathrm{a} / \AA$ & $10.688(2)$ \\
$\mathrm{b} / \AA$ & $12.152(3)$ \\
$\mathrm{c} / \AA$ & $17.471(4)$ \\
$\alpha /{ }^{\circ}$ & $90.77(7)$ \\
$\beta /{ }^{\circ}$ & $97.60(7)$ \\
$\gamma /{ }^{\circ}$ & $111.42(6)$ \\
$\mathrm{Volume} / \AA^{3}$ & $2089.0(8)$ \\
$\mathrm{Z}$ & 4 \\
$\rho_{\text {calcg }} / \mathrm{cm}^{3}$ & 1.232 \\
$\mu / \mathrm{mm}^{-1}$ & 0.074 \\
$\mathrm{~F}(000)$ & 816.0
\end{tabular}


Crystal size $/ \mathrm{mm}^{3}$

Radiation

$2 \Theta$ range for data collection/ ${ }^{\circ}$

Index ranges

Reflections collected

Independent reflections

Data/restraints/parameters

Goodness-of-fit on $\mathrm{F}^{2}$

Final $R$ indexes $[\mathrm{I}>=2 \sigma(\mathrm{I})]$

Final R indexes [all data]

Largest diff. peak/hole / e $\AA^{-3}$
$0.20 \times 0.15 \times 0.1$

$\operatorname{MoK} \alpha(\lambda=0.71073)$

1.178 to 28.455

$-14 \leq \mathrm{h} \leq 14,-16 \leq \mathrm{k} \leq 16,-23 \leq 1 \leq 23$

25655

$6573\left[\mathrm{R}_{\text {int }}=0.0325, \mathrm{R}_{\text {sigma }}=0.0420\right]$

$10402 / 0 / 541$

1.006

$\mathrm{R}_{1}=0.0580, \mathrm{wR}_{2}=0.1273$

$\mathrm{R}_{1}=0.1484, \mathrm{wR}_{2}=0.1628$

$0.18 /-0.18$

Table S5. Crystal data and structure refinement for TPQ-TPA.

\begin{tabular}{|c|c|}
\hline Empirical formula & $\mathrm{C}_{39} \mathrm{H}_{28} \mathrm{~N}_{2}$ \\
\hline Formula weight & 524.63 \\
\hline Temperature/K & 153.15 \\
\hline Crystal system & triclinic \\
\hline Space group & $\mathrm{P}-1$ \\
\hline $\mathrm{a} / \AA$ & $10.313(2)$ \\
\hline $\mathrm{b} / \AA$ & $13.428(3)$ \\
\hline $\mathrm{c} / \AA$ & $20.210(4)$ \\
\hline$\alpha /^{\circ}$ & $90.88(3)$ \\
\hline$\beta /{ }^{\circ}$ & $95.71(3)$ \\
\hline$\gamma /{ }^{\circ}$ & $90.51(3)$ \\
\hline Volume $/ \AA^{3}$ & $2784.4(10)$ \\
\hline $\mathrm{Z}$ & 4 \\
\hline$\rho_{\text {calc }} \mathrm{g} / \mathrm{cm}^{3}$ & 1.252 \\
\hline$\mu / \mathrm{mm}^{-1}$ & 0.073 \\
\hline $\mathrm{F}(000)$ & 1104.0 \\
\hline Crystal size $/ \mathrm{mm}^{3}$ & $0.24 \times 0.21 \times 0.05$ \\
\hline Radiation & $\operatorname{MoK} \alpha(\lambda=0.71073)$ \\
\hline $2 \Theta$ range for data collection ${ }^{\circ}$ & 2.026 to 49.998 \\
\hline Index ranges & $-12 \leq \mathrm{h} \leq 11,-14 \leq \mathrm{k} \leq 15,-23 \leq 1 \leq 24$ \\
\hline Reflections collected & 19750 \\
\hline Independent reflections & $9731\left[\mathrm{R}_{\text {int }}=0.0611, \mathrm{R}_{\mathrm{sigma}}=0.0786\right]$ \\
\hline Data/restraints/parameters & $9731 / 0 / 739$ \\
\hline Goodness-of-fit on $\mathrm{F}^{2}$ & 1.192 \\
\hline Final $R$ indexes $[\mathrm{I}>=2 \sigma(\mathrm{I})]$ & $\mathrm{R}_{1}=0.0880, \mathrm{wR}_{2}=0.2392$ \\
\hline Final $\mathrm{R}$ indexes [all data] & $\mathrm{R}_{1}=0.1112, \mathrm{wR}_{2}=0.2773$ \\
\hline Largest diff. peak/hole / e $\AA^{-3}$ & $0.50 /-0.57$ \\
\hline
\end{tabular}


Table S6. Crystal data and structure refinement for TPQ-CN.

\begin{tabular}{|c|c|}
\hline Empirical formula & $\mathrm{C}_{35} \mathrm{H}_{26} \mathrm{~N}_{2}$ \\
\hline Formula weight & 474.58 \\
\hline Temperature/K & 153.15 \\
\hline Crystal system & monoclinic \\
\hline Space group & $\mathrm{P} 2{ }_{1} / \mathrm{n}$ \\
\hline $\mathrm{a} / \AA$ & $10.481(2)$ \\
\hline $\mathrm{b} / \AA$ & $10.317(2)$ \\
\hline $\mathrm{c} / \AA$ & $24.012(5)$ \\
\hline$\alpha /^{\circ}$ & 90 \\
\hline$\beta /^{\circ}$ & $93.76(3)$ \\
\hline$\gamma /{ }^{\circ}$ & 90 \\
\hline Volume $/ \AA^{3}$ & 2591.0(9) \\
\hline $\mathrm{Z}$ & 4 \\
\hline$\rho_{\text {calc }} \mathrm{g} / \mathrm{cm}^{3}$ & 1.217 \\
\hline$\mu / \mathrm{mm}^{-1}$ & 0.071 \\
\hline $\mathrm{F}(000)$ & 1000.0 \\
\hline Crystal size $/ \mathrm{mm}^{3}$ & $0.24 \times 0.23 \times 0.2$ \\
\hline Radiation & $\operatorname{MoK} \alpha(\lambda=0.71073)$ \\
\hline $2 \Theta$ range for data collection $/^{\circ}$ & 3.4 to 54.908 \\
\hline Index ranges & $-13 \leq \mathrm{h} \leq 13,-13 \leq \mathrm{k} \leq 12,-31 \leq 1 \leq 27$ \\
\hline Reflections collected & 20437 \\
\hline Independent reflections & $5915\left[\mathrm{R}_{\mathrm{int}}=0.0343, \mathrm{R}_{\mathrm{sigma}}=0.0282\right]$ \\
\hline Data/restraints/parameters & $5915 / 0 / 335$ \\
\hline Goodness-of-fit on $\mathrm{F}^{2}$ & 1.271 \\
\hline Final $R$ indexes $[\mathrm{I}>=2 \sigma(\mathrm{I})]$ & $\mathrm{R}_{1}=0.0593, \mathrm{wR}_{2}=0.1722$ \\
\hline Final $\mathrm{R}$ indexes [all data] & $\mathrm{R}_{1}=0.0709, \mathrm{wR}_{2}=0.1974$ \\
\hline Largest diff. peak/hole / e $\AA^{-3}$ & $0.55 /-0.51$ \\
\hline
\end{tabular}

\section{References}

(1) Liu, T.; Winter, M.; Thierry, B. Quasi-spherical microwells on superhydrophobic substrates for long term culture of multicellular spheroids and high throughput assays. Biomaterials 2014, 35, 6060-6068. 